\title{
Performance of PV Generation Feedback \\ Controllers: Power Factor versus Volt-VAR Control Strategies
}

\author{
Ashish Agrawal \\ fulfillment of the requirements for the degree of \\ Master of Science \\ in \\ Electrical Engineering \\ Robert P. Broadwater, Chair \\ Virgilio A. Centeno \\ Jaime De La Reelopez
}

Thesis submitted to the faculty of the Virginia Polytechnic Institute and State University in partial

April 23 ${ }^{\text {rd }} 2015$

Blacksburg, Virginia

Keywords: Constant Power Factor Controllers, Feedback Controllers, PV Generation, Voltage Control, Volt-VAR Controllers 
Performance of PV Generation Feedback Controllers: Power Factor versus Volt-VAR Control Strategies

Ashish Agrawal

\section{ABSTRACT}

The variable nature of photovoltaic (PV) generation can cause voltage fluctuations in power distribution systems. Feedback control can be used to minimize the voltage fluctuations. This thesis presents the results obtained from comparing the control performance of two types of PV generation feedback control, namely Volt-VAR control and constant power factor control. A three minute PV generation transient is used to evaluate controller performance, where the transient data used originated from one second measurements taken on an actual PV generator. Using the three minute transient, a set of parametric studies are performed on both feedback control strategies. The performance of the control strategies are compared as to voltage control on the distribution feeder and also to the effect that the control may have on transmission system voltage. In considering transmission system voltage, the reactive power drawn from the substation during the transient is evaluated. Simulation results suggest that the choice of control to be implemented should be based on both transmission and distribution system operational concerns. 


\section{Acknowledgements}

I would like to thank all my well-wishers, including my friends and family, for their support and encouragement during my studies. I would also like to extend my heartfelt gratitude to my advisor and other committee members who guided me through the process of conducting research. 


\section{Table of Contents}

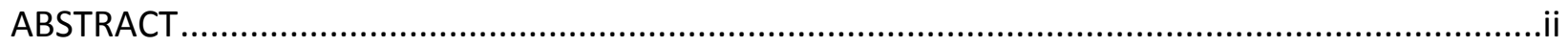

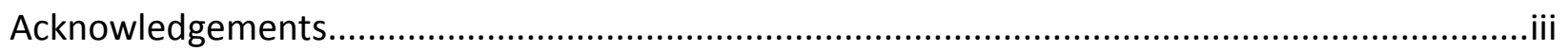

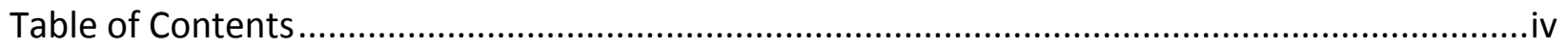

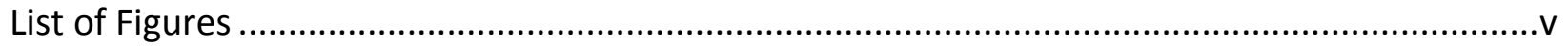

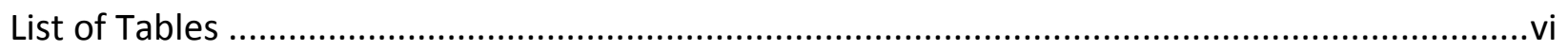

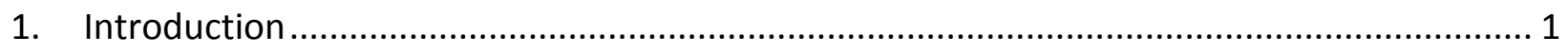

2. Constant Power Factor and Volt-VAR Controllers.......................................................... 4

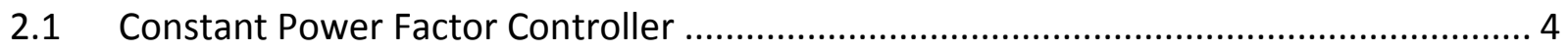

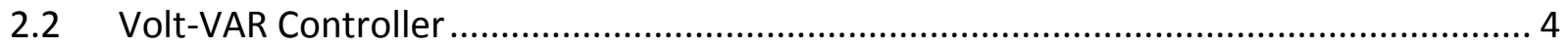

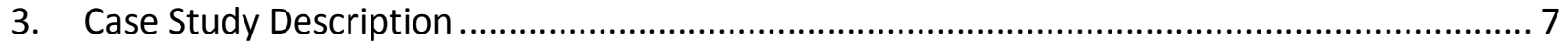

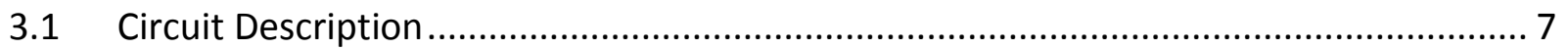

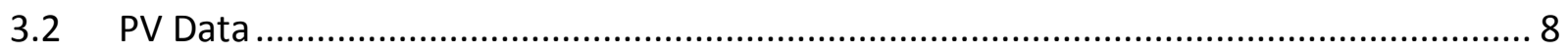

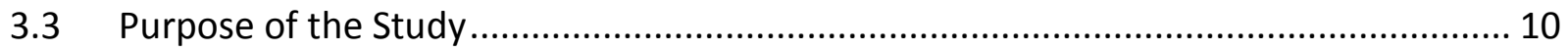

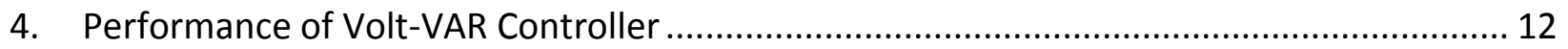

5. Performance of Constant Power Factor Controller.................................................. 19

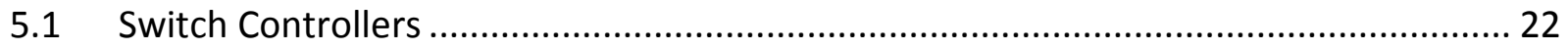

6. Comparison of Controller Performances................................................................... 24

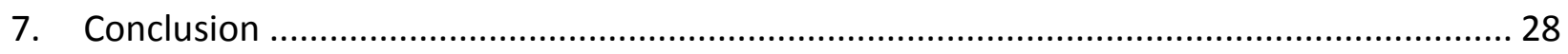

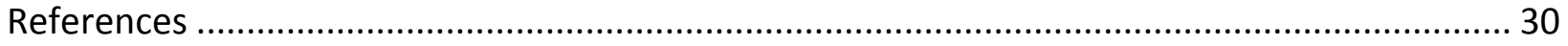




\section{List of Figures}

Figure 1.1 Nevada PV plant output on a sunny day and a partly cloudy day ............................. 2

Figure 2.1 Volt-VAR controller characteristic ................................................................. 5

Figure 2.2 Volt-VAR control block diagram...................................................................... 5

Figure 3.1 Circuit under study (IEEE 123 bus system) ................................................... 8

Figure 3.2 Variable PV generation over the analysis time period .......................................... 9

Figure 3.3 Fraction of load supplied by the PV generator ................................................ 9

Figure $4.1 Q_{\text {deviation }}$ vs slope of Volt-VAR controller characteristic ........................................ 14

Figure $4.2 \mathrm{Q}_{\text {avg }}$ vs slope of Volt-VAR controller characteristic............................................. 15

Figure $4.3 \Delta V$ vs slope of Volt-VAR controller characteristic................................................... 16

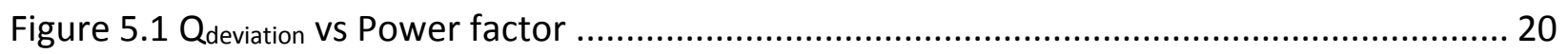

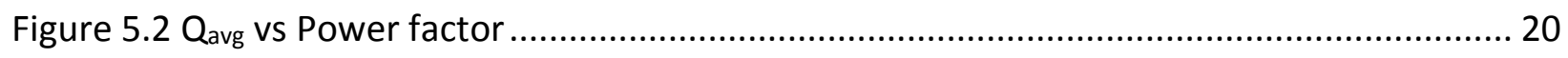

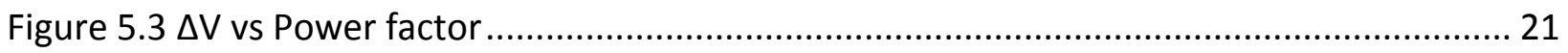

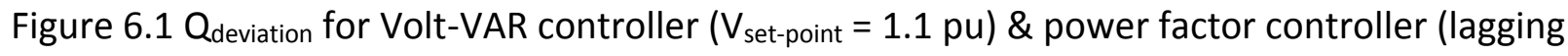

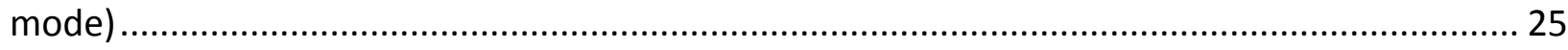

Figure 6.2 $\mathrm{Q}_{\mathrm{avg}}$ for Volt-VAR controller $\left(\mathrm{V}_{\text {set-point }}=1.1 \mathrm{pu}\right)$ \& power factor controller (lagging

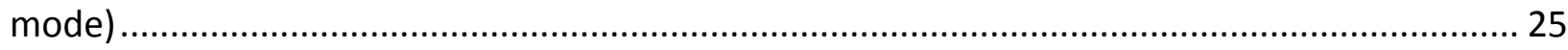

Figure 6.3 $\Delta \mathrm{V}$ for Volt-VAR controller $\left(\mathrm{V}_{\text {set-point }}=1.1 \mathrm{pu}\right)$ \& power factor controller (lagging

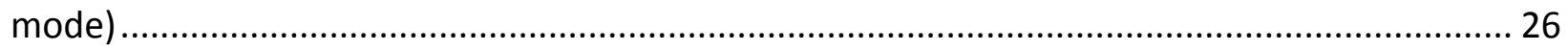

Figure 6.4 $\mathrm{Q}_{\text {deviation }}$ for Volt-VAR controller $\left(\mathrm{V}_{\text {set-point }}=1.1 \mathrm{pu}\right)$ \& power factor controller (leading

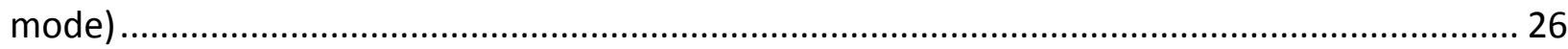

Figure 6.5 $\mathrm{Q}_{\text {avg }}$ for Volt-VAR controller $\left(\mathrm{V}_{\text {set-point }}=1.1 \mathrm{pu}\right)$ \& power factor controller (leading

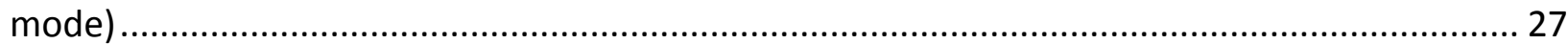

Figure 6.6 $\Delta \mathrm{V}$ for Volt-VAR controller $\left(\mathrm{V}_{\text {set-point }}=1.1 \mathrm{pu}\right)$ \& power factor controller (leading mode) 


\section{List of Tables}

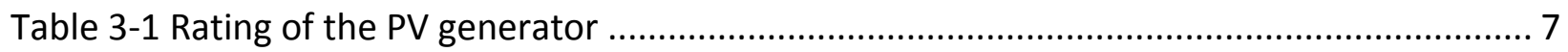

Table 3-2 Circuit Loading in absence of PV generator ..................................................... 7

Table 3-3 PV generation variation over analysis time period................................................ 9

Table 3-4 Maximum rates of increase and decrease in PV generation ................................... 10

Table 4-1 $Q_{\text {deviation }}$ vs slope of volt-var controller characteristic with varying voltage set-points 17

Table 4-2 Q avg vs slope of volt-var controller characteristic with varying voltage set-points ...... 17

Table 4-3 $\Delta \mathrm{V}$ vs slope of volt-var controller characteristic with varying voltage set-point.......... 18

Table 5-1 Performance of constant power factor controller in power factor lagging mode....... 21

Table 5-2 Performance of constant power factor controller in power factor leading mode ...... 21

Table 5-3 Time periods when solar generation continuously increases or decreases................ 23

Table 5-4 Performance of constant power factor controller when the solar generation

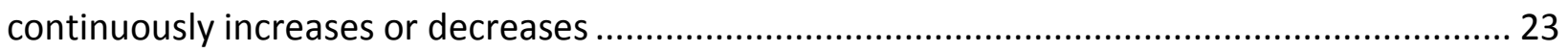




\section{Introduction}

The growing demand for electric power coupled with depleting conventional sources of power has led to efforts to increase power generation worldwide using renewable sources of energy. Solar energy is one of the fastest growing renewable energy sources. Solar photovoltaic (PV) technologies have the potential to meet much of the electricity demand in the United States for the next several decades and are projected to supply nearly 14\% of US electricity demand by 2030 and $27 \%$ of the demand by 2050 [1]. One advantage of PV technology is generating electricity without harming the environment.

Though PV generation provides an attractive alternative to fossil fuels, production of power using PV presents a number of challenges due to the variable nature of the solar resource received on the surface of the earth [2]. For instance, a PV plant output can vary by $90 \%$ over a few seconds on a partly cloudy day, as shown in Figure 1.1 [3]. This rapid variation in the amount of power generated by PV systems leads to voltage fluctuations, reverse power flows, voltage and current unbalances, and power losses in both the transmission and distribution systems [4, 5]. One of the biggest challenges in the distribution system is to maintain the customer voltage level in its allowed range [6].

Reactive power control strategies can be used to minimize the voltage fluctuations in distribution systems. Traditionally constant power factor control or constant reactive power control strategies have been used to regulate voltage levels at the PV generators themselves. Reference [7] discusses a reactive power control strategy based on constant power factor control and suggests that applying constant power factor control may overheat the PV inverter by drawing excessive reactive power. Reference [8] analyses the constant power factor control of the power conditioning system of a large-scale ( $2 \mathrm{MW}$ ) PV system and suggests that it is possible to achieve voltage regulation using the constant power factor control. A power factor control strategy based on sensitivity analysis is discussed in [9], where it is proposed that voltage regulation can be achieved with less reactive power consumption if a location dependent power factor value is assigned to each PV inverter. 

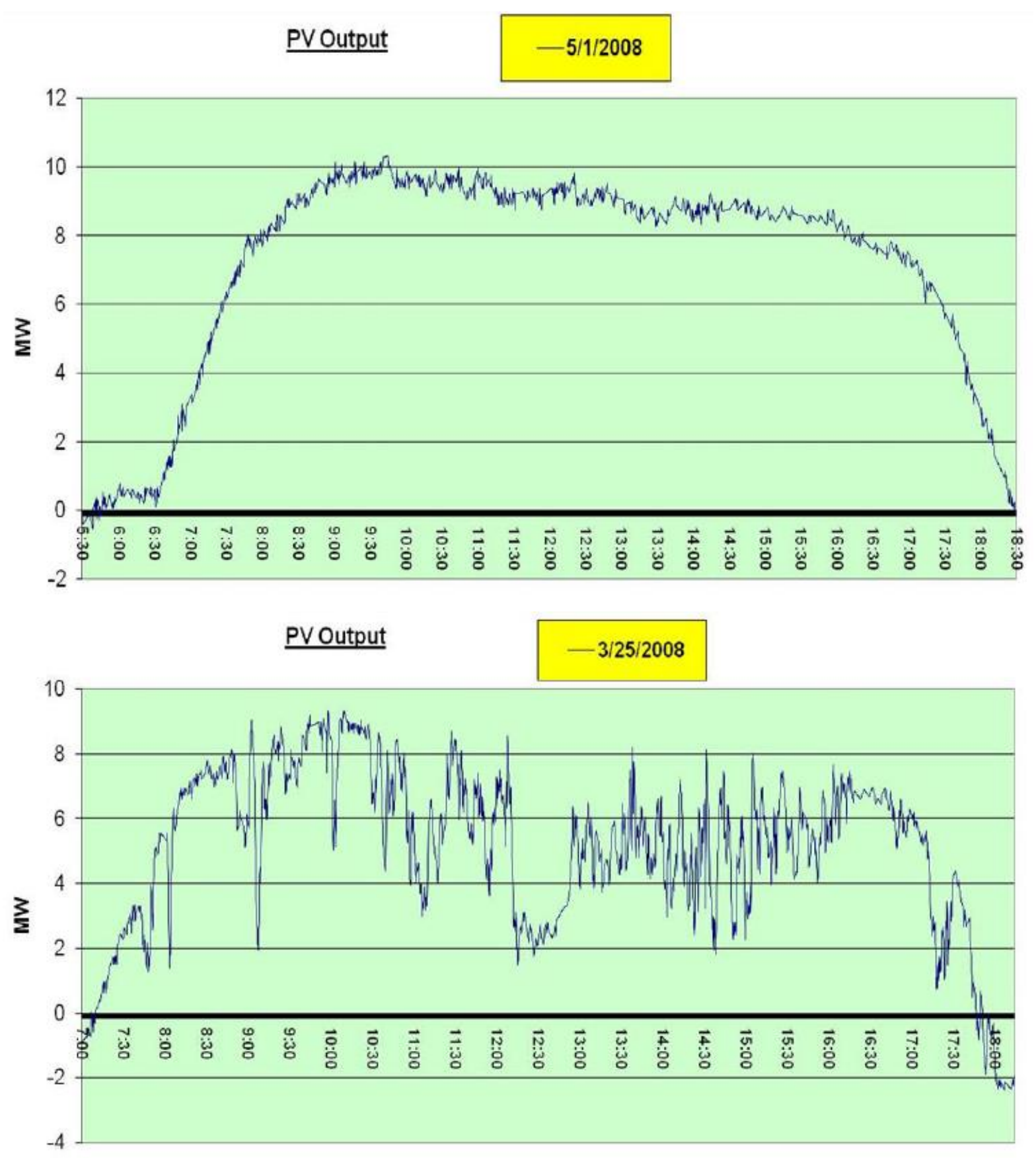

Figure 1.1 Nevada PV plant output on a sunny day (top) and a partly cloudy day (bottom)

(Source: North American Electric Reliability Corporation, "Accommodating high levels of variable generation." April 2009. Used under fair use.)

Volt-VAR controllers are advanced controllers used to regulate voltage levels. The performance of a Volt-VAR droop controller has been examined in $[10,11]$, where it is suggested that Volt-VAR control can effectively minimize voltage fluctuations caused by the intermittent PV generation. 
This thesis studies and evaluates the performance of two feedback controlled strategies, namely Volt-VAR control and constant power factor control. The comparison involves voltage control considerations for both the distribution and the transmission systems. Voltage control for the transmission system will be measured by evaluating which controller draws the least reactive power from the distribution substation. Voltage control for the distribution system will be measured by evaluating which controller can best minimize customer level voltage deviations. Section 2 of this thesis describes the two types of controllers. The circuit under study and the PV data used in the study are described in section 3. Sections 4 and 5 discuss the performance of VoltVAR and constant power factor controllers respectively. A comparison of performances of the controllers has been discussed in section 6 . Section 7 discusses the conclusion and scope for future study. 


\section{Constant Power Factor and Volt-VAR Controllers}

This section describes the two types of controllers and discusses the parameters associated with each type of controller.

\subsection{Constant Power Factor Controller}

Constant power factor controllers have been traditionally used in PV generation to regulate voltage. As the name suggests the PV generation is operated in a constant power factor mode. The power factor can be leading or lagging. In order to keep the PV generator at a constant power factor, the ratio of the active power to the reactive power is maintained constant. This is achieved by varying the reactive power output with changes in the active power output to maintain a constant power factor.

In constant power factor control mode the terminal voltage of the generator is not monitored. The controller monitors the power factor of the generator's power output and accordingly controls the VAR output of the PV generator to keep the power factor at the set point [12].

\subsection{Volt-VAR Controller}

A Volt-VAR controller regulates the voltage by supplying reactive power if the line voltage falls below a specified voltage set-point and absorbing reactive power if the line voltage is above the set-point. A typical characteristic used in Volt-VAR feedback control is illustrated in Figure 2.1 [13]. The terminal voltage of the PV generator is represented on the horizontal axis and the reactive power supplied by the PV generator is represented on the vertical axis. The control block diagram for the volt-var controller is shown in Figure 2.2 [13]. The basic principle underlying this control is that if the terminal voltage of the generator falls below the voltage set-point, the generator starts supplying reactive power which leads to an increase in the terminal voltage. On the other hand, if the terminal voltage exceeds the voltage set-point, the PV generator starts absorbing reactive power which leads to a decrease in the terminal voltage. 


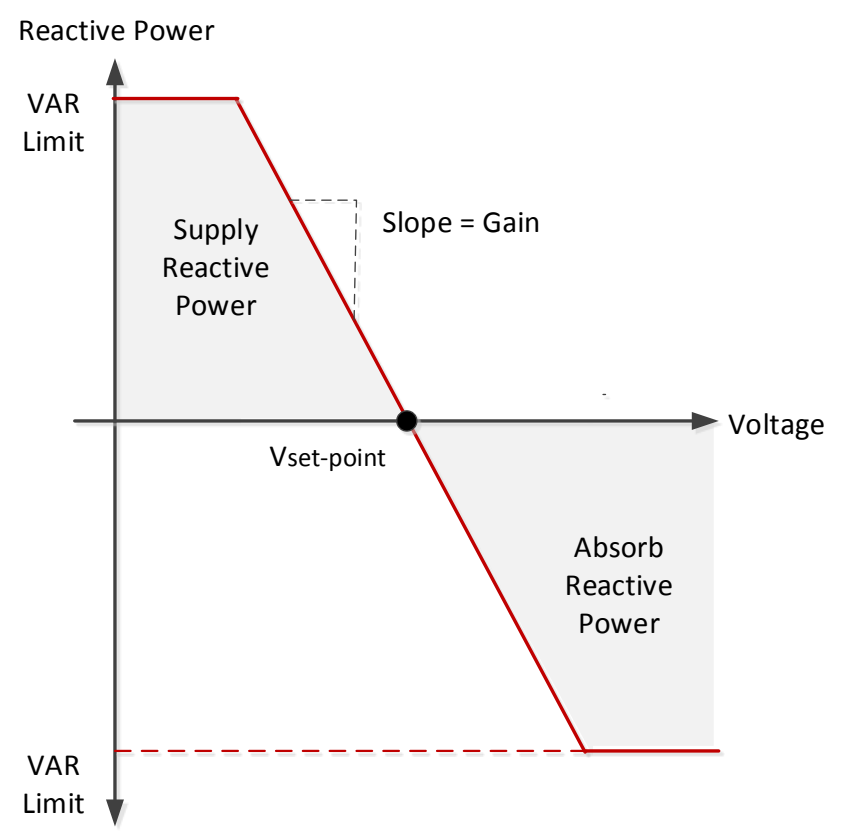

Figure 2.1 Volt-VAR controller characteristic

(Source: J. Jung, A. Onen, K. Russell, R.P. Broadwater, S. Steffel, and A. Dinkel, "Configurable, hierarchical, modelbased, scheduling control with photovoltaic generators in power distribution circuits", Renewable Energy, vol. 76, pp. 318-329, 2015. Adapted under fair use.)

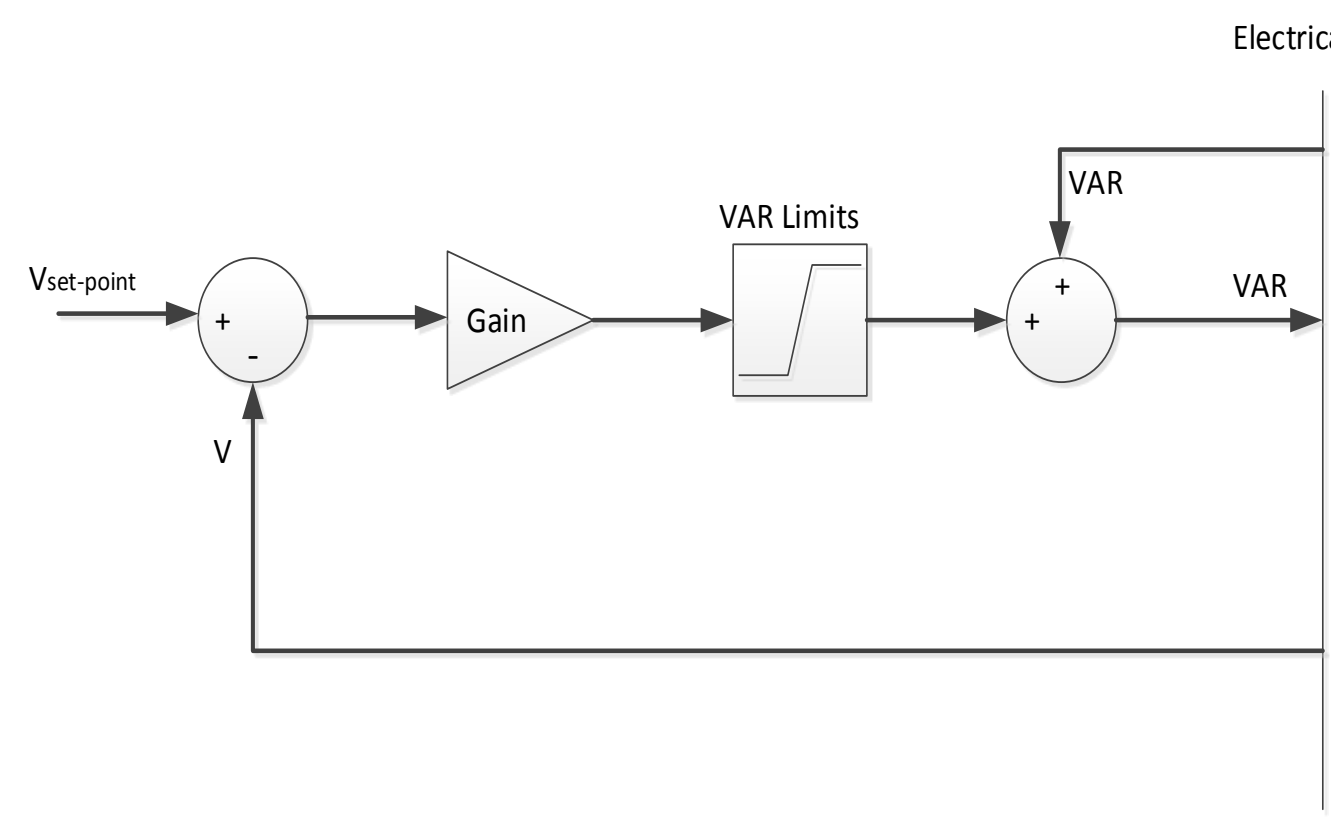

Figure 2.2 Volt-VAR control block diagram

(Source: J. Jung, A. Onen, K. Russell, R.P. Broadwater, S. Steffel, and A. Dinkel, "Configurable, hierarchical, modelbased, scheduling control with photovoltaic generators in power distribution circuits", Renewable Energy, vol. 76, pp. 318-329, 2015. Adapted under fair use.) 
A Volt-VAR controller is characterized by three parameters which are

- Slope of the Volt-VAR controller characteristic

It should be noted that the slope of the volt-var characteristic is always negative. However, we will use the absolute value of the slope in later sections for analysis purposes. The block representing 'Gain' in Figure 2.2 refers to the slope of the volt-var controller. The slope of the volt-var controller curve is a dimensionless quantity as it represents the change of percentage available VARs with respect to the change in per unit voltage set-point.

The slope of the Volt-VAR controller characteristic is measured in terms of the angle made by the Volt-VAR characteristic with the horizontal axis. The angle made by the Volt-VAR characteristic with the horizontal axis is measured in the clockwise direction and lies between 0 and 90 degrees. This way, an increase in the angle made by the characteristic with the horizontal axis represents an increase in the steepness of the characteristic.

- Voltage set-point

The voltage set-point, as shown in Figure 2.1 is the voltage level when the controller changes its operation from supplying reactive power to absorbing reactive power. The volt-var curve can be shifted along the horizontal axis to change the voltage set-point.

- Lower and upper limits on VAR generation

The amount of reactive power which can be absorbed or supplied by the volt-var controller can be fixed at a certain percentage of the VAR rating of the PV generator. The block representing 'VAR Limits' in Figure 2.2 refers to the percentage available VAR of the volt-var controller.

Unlike the power factor controller, the Volt-VAR controller monitors the terminal voltage of the PV generator and uses the voltage error to control the reactive power output of the generator [12]. 


\section{Case Study Description}

This section describes the circuit used for the given study, the solar data used, and the purpose of the study.

\subsection{Circuit Description}

Here the IEEE 123-bus system will be used to compare the performance of constant power factor and Volt-VAR controllers. Figure 3.1 shows the circuit under study. Different points are labeled in the figure to show the locations of the PV injections, the substation, feeder end points (where voltage measurements are taken), and the recloser (where the reactive power flow from the substation is measured).

It should be noted that three-phase voltages are measured at two feeder end points (as denoted by the two sets of three phase voltages $\{\mathrm{V} 1, \mathrm{~V} 2, \mathrm{~V} 3\}$ and $\{\mathrm{V} 4, \mathrm{~V} 5, \mathrm{~V} 6\}$ in Figure 3.1), and phase $\mathrm{C}$ voltage is measured at the third feeder end point (as denoted by V7 in Figure 3.1). The reactive power flow is denoted by $\mathrm{Q}_{\text {sub }}$ in Figure 3.1. Table 3-1 shows the rating of the PV generator and Table 3-2 presents the circuit loading in the absence of the PV generator. It should be noted that the circuit loading does not change during the simulations.

Table 3-1 Rating of the PV generator

\begin{tabular}{|c|c|}
\hline kW & 2300 \\
\hline kVA & 2576 \\
\hline kVar Limit & 2576 \\
\hline Volts & 480 \\
\hline kVar @ Rated kW & 1160.1 \\
\hline
\end{tabular}

Table 3-2 Circuit Loading in absence of PV generator

\begin{tabular}{|c|c|c|}
\hline & $\begin{array}{c}\text { Real Power } \\
(\mathbf{k W})\end{array}$ & $\begin{array}{c}\text { Reactive Power } \\
\text { (kVAR) }\end{array}$ \\
\hline Phase A & 1455.21 & 580.71 \\
\hline Phase B & 958.63 & 340.74 \\
\hline Phase C & 1185.79 & 398.58 \\
\hline Total & 3599.63 & 1320.03 \\
\hline
\end{tabular}




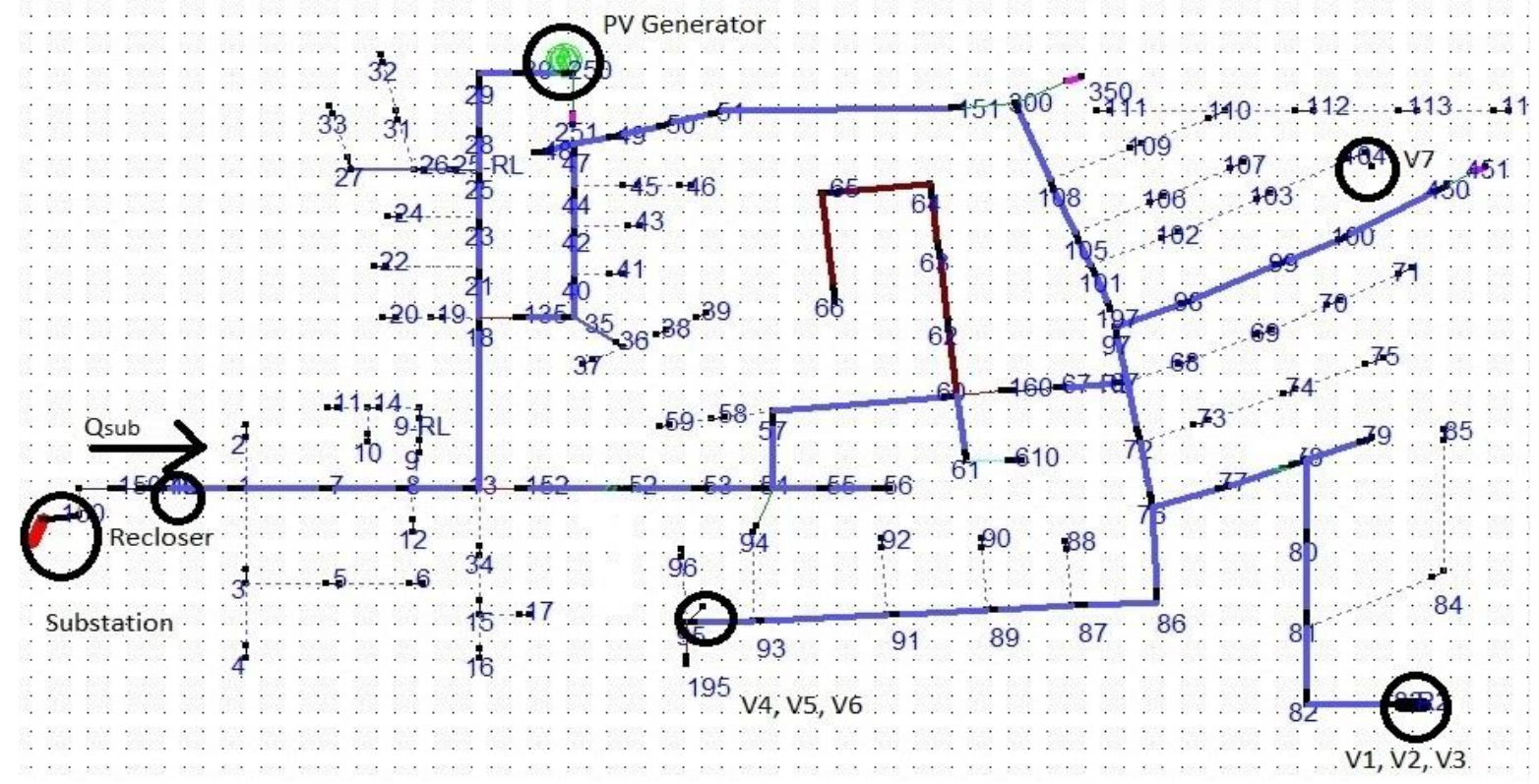

Figure 3.1 Circuit under study (IEEE 123 bus system)

\subsection{PV Data}

The PV generation data used in this study is derived from one second PV generation data obtained from an actual PV generator. The actual PV generation data was collected over a year, and in the study here a small sample of the data was used, from 14:22:00 $(t=0)$ to 14:25:00 $(t=$ 180 s) on a given day in April. Figure 3.2 shows the PV generation data used in the study here over the period of analysis for the three phases.

Table 3-3 shows the percentage variation in PV generation over the three phases. Figure 3.3 presents the variation in the fraction of load supplied by the PV generator during the analysis time period. The percentage of load supplied by the PV generator varies from $53.4 \%$ to $16.2 \%$ in phase $A$, from $79.8 \%$ to $24.2 \%$ in phase $B$, and from $62.8 \%$ to $18.2 \%$ in phase C. Table $3-4$ shows the maximum rates of increase and decrease in PV generation and the time periods of those changes. 


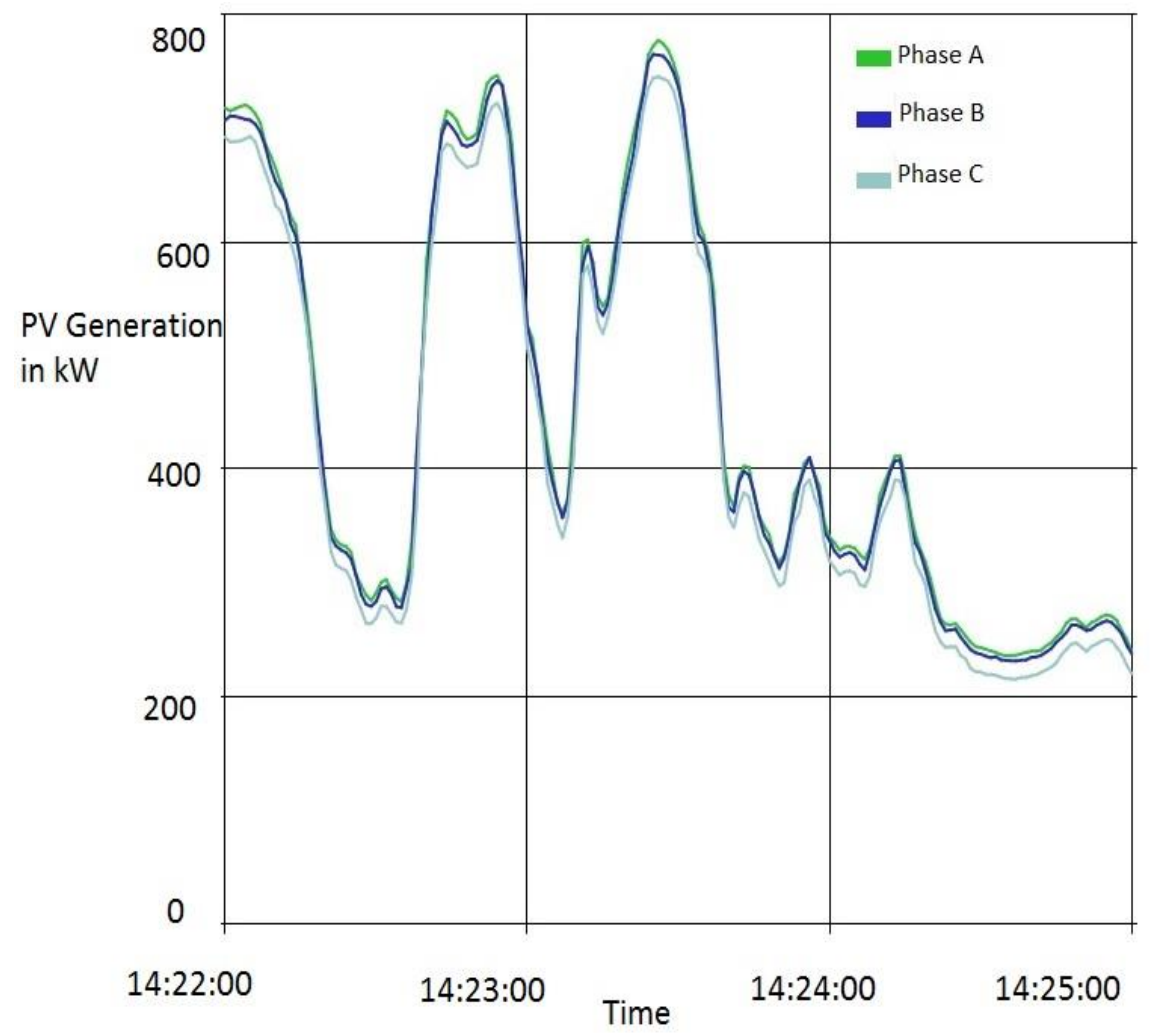

Figure 3.2 Variable PV generation over the analysis time period

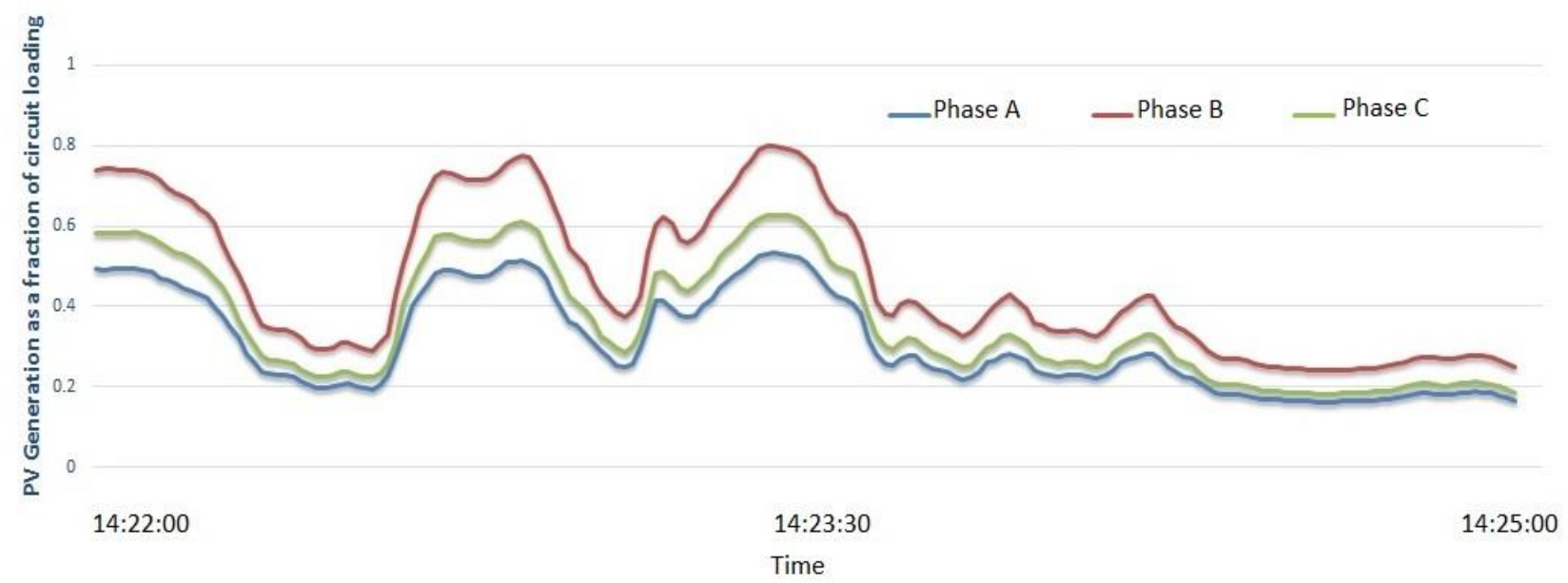

Figure 3.3 Fraction of load supplied by the PV generator

Table 3-3 PV generation variation over analysis time period

\begin{tabular}{|c|c|c|c|}
\hline PV Data in (kW) & $\begin{array}{c}\text { Maximum } \\
\text { Generation }\end{array}$ & $\begin{array}{c}\text { Minimum } \\
\text { Generation }\end{array}$ & $\begin{array}{c}\text { Percentage } \\
\text { Variation }\end{array}$ \\
\hline Phase A & 776.996 & 236.101 & 69.61 \\
\hline Phase B & 764.6 & 231.517 & 69.72 \\
\hline Phase C & 744.974 & 215.506 & 71.07 \\
\hline Total & 2286.57 & 683.124 & 70.12 \\
\hline
\end{tabular}


Table 3-4 Maximum rates of increase and decrease in PV generation

\begin{tabular}{|l|c|c|c|c|}
\hline & \multicolumn{2}{|c|}{ PV generation increasing } & \multicolumn{2}{c|}{ PV generation decreasing } \\
\cline { 2 - 5 } & $\begin{array}{c}\text { Maximum rate of } \\
\text { change }(\mathrm{kW} / \mathrm{s})\end{array}$ & Time of change & $\begin{array}{c}\text { Maximum rate of } \\
\text { change }(\mathrm{kW} / \mathrm{s})\end{array}$ & \begin{tabular}{c} 
Time of change \\
\hline Phase A
\end{tabular} \\
& 29.053 & $14: 22: 35-$ & 27.499 & $14: 22: 54-$ \\
& & $14: 22: 48$ & & $14: 23: 07$ \\
\hline Phase B & 28.984 & $14: 22: 35-$ & 27.461 & $14: 22: 54-$ \\
& & $14: 22: 48$ & & $14: 23: 07$ \\
\hline Phase C & 28.615 & $14: 22: 35-$ & 27.314 & $14: 22: 54-$ \\
& & $14: 22: 48$ & & $14: 23: 07$ \\
\hline
\end{tabular}

\subsection{Purpose of the Study}

The aim is to evaluate controller performance relative to reactive power drawn from the substation and relative to customer level voltage deviations. Reactive power effects at the substation will be measured with two variables, the maximum and the average reactive power drawn from the substation, as measured by $Q_{\max }$ and $Q_{a v g}$, respectively. The reactive power drawn from the substation is denoted by $Q_{\text {sub. }} Q_{\max }$ is defined as the maximum reactive power drawn from the substation over the analysis time period. $Q_{\max }$ will be evaluated in terms of its deviation from the reactive power drawn from the substation in the absence of the PV generator, denoted by $Q_{\text {ref. }}$ As can be seen from Table 3-2, the reactive power drawn from the substation in the absence of PV generator is 1320 kVAR (i.e., $Q_{\text {ref }}=1320$ kVAR). The deviation of $Q_{\max }$ from $Q_{\text {ref }}$ is denoted by $Q_{\text {deviation. }}$ Customer level voltage deviation, as denoted by $\Delta \mathrm{V}$, is measured as the sum of the difference between $\left(V_{i}\right)_{\max }$ and $\left(V_{i}\right)_{\min }$ for each of the seven feeder voltages during the period of analysis. $\mathrm{Q}_{\max }, \mathrm{Q}_{\mathrm{avg}}, \mathrm{Q}_{\text {deviation }}$ and $\Delta \mathrm{V}$ are computed by:

$$
\begin{aligned}
& \mathrm{Q}_{\text {max }}=\operatorname{Max}\left(\left(\mathrm{Q}_{\text {sub }}\right)_{\mathrm{t}}\right) \\
& \mathrm{Q}_{\text {deviation }}=\mathrm{Q}_{\max }-\mathrm{Q}_{\text {ref }} \\
& \mathrm{Q}_{\text {avg }}=\frac{1}{181} \sum_{\mathrm{t}=0}^{\mathrm{t}=180 \mathrm{~s}}\left(\mathrm{Q}_{\text {sub }}\right)_{\mathrm{t}} \\
& \left(\mathrm{V}_{\mathrm{i}}\right)_{\max }=\operatorname{Max}\left(\left(\mathrm{V}_{\mathrm{i}}\right)_{\mathrm{t}}\right) \\
& \left(\mathrm{V}_{\mathrm{i}}\right)_{\min }=\operatorname{Min}\left(\left(\mathrm{V}_{\mathrm{i}}\right)_{\mathrm{t}}\right) \\
& \Delta \mathrm{V}_{\mathrm{i}}=\left(\mathrm{V}_{\mathrm{i}}\right)_{\max }-\left(\mathrm{V}_{\mathrm{i}}\right)_{\min } \\
& \Delta \mathrm{V}=\sum_{\mathrm{i}=1}^{\mathrm{i}=7} \Delta \mathrm{V}_{\mathrm{i}}
\end{aligned}
$$


where $\mathrm{i}$ varies from 1 to 7 and $t$ varies from 0 to $180 \mathrm{~s}$. In the above equations, $\left(Q_{\text {sub }}\right)_{t}$ represents the reactive power drawn from the substation at time ' $t$ ' and $\left(V_{i}\right)_{t}$ represents the ith voltage measurement at time ' $\mathrm{t}$ ', where $0<=\mathrm{t}<=180$.

Quasi-steady state power flow analysis is used to analyze the response of the system at each second. In practice, the controller feedback generally operates faster than the sample rate of 1 second used here. In actual practice, the inverter controls may have a sample rate of few hundred milliseconds, which is still large compared to the electrical time constants of the distribution feeders. 


\section{Performance of Volt-VAR Controller}

In order to study the performance of Volt-VAR feedback control during PV transients, simulations were performed by varying the parameters of the Volt-VAR controller. As discussed in section 2.2, a Volt-VAR controller is characterized by the slope of the Volt-VAR controller characteristic, voltage set-point, and lower and upper limits on VAR generation. For the present study, the lower and upper limits on the VAR generation were kept constant at $90 \%$ of the VAR rating of the PV generator, and slope of the Volt-VAR controller characteristic and voltage setpoint were varied.

Here the slope of the Volt-VAR controller characteristic is measured in terms of the angle made by the Volt-VAR characteristic with the horizontal axis. Here the angle made by the Volt-VAR characteristic with the horizontal axis is measured in a clockwise direction and lies between 0 and 90 degrees. This way, an increase in the angle made by the characteristic with the horizontal axis represents an increase in the steepness of the characteristic.

Figure 4.1 (a \& b) shows the variation in deviation ( $\left.Q_{\text {deviation}}\right)$ of maximum reactive power $\left(Q_{\max }\right)$ drawn from the substation from the reference value $\left(Q_{\text {ref }}\right)$ with the angle made by the Volt-VAR controller characteristic with the horizontal axis and absolute value of the slope of the characteristic respectively during the PV transient. The vertical axis of the graph in Figure 4.1 represents $Q_{\text {deviation }}$ and the horizontal axis represents the angle of the Volt-VAR controller characteristic slope in Figure 4.1 (a) and absolute value of the slope in Figure 4.1 (b). Figures 4.2 and 4.3 show the variation in the average reactive power drawn from the substation $\left(Q_{\text {avg }}\right)$ and voltage deviation $(\Delta \mathrm{V})$, respectively, with respect to the angle made by the Volt-VAR controller characteristic and slope of the Volt-VAR controller characteristic. The following can be observed from figures 4.1 and 4.2 :

- $Q_{\text {deviation }}$ remains close to zero until the angle made by the Volt-VAR controller characteristic with the horizontal axis reaches close to 70 degrees, despite the fact that there is significant PV generation during the transient. This is because below 70 degrees

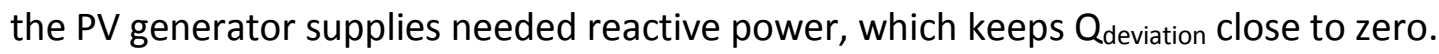


- $\mathrm{Q}_{\text {deviation }}$ and $\mathrm{Q}_{\text {avg }}$ remain insensitive to the variation in slope of the Volt-VAR controller characteristic until the angle reaches 70 degrees. After that, $Q_{\text {deviation }}$ and $Q_{\text {avg }}$ either increase or decline depending upon the voltage set-point of the controller.

- $Q_{\text {deviation }}$ and $\mathrm{Q}_{\mathrm{avg}}$ are the lowest when the voltage set-point is $1.1 \mathrm{pu}$. This is because when the terminal voltage of the generator is set to a higher value, the PV generator starts supplying more reactive power, leading to a decrease in maximum and average reactive power drawn from the substation.

From Figure 4.3 it can be seen that:

- The voltage deviation $(\Delta \mathrm{V})$ is almost insensitive to the slope of the Volt-VAR controller characteristic when the angle made by the characteristic with the horizontal axis varies from 45 to 70 degrees for voltage set-points of 1 pu and 1.05 pu. After 70 degrees, $\Delta V$ dips and then again peaks at different angles depending on the voltage set-point of the VoltVAR controller.

- $\quad$ For the voltage set-point of $1.1 \mathrm{pu}, \Delta \mathrm{V}$ constantly decreases when the angle varies from 45 degrees to around 72 degrees. After that, it starts increasing.

- A voltage set point of 1.1 pu gives the lowest $\Delta \mathrm{V}$.

Based on figures 4.1, 4.2, and 4.3, a Volt-VAR controller with a voltage set-point of 1.1 pu and which makes an angle of 65-70 degrees with the horizontal axis in the clockwise direction is selected for comparison with the performance of the constant power factor controller. While controller settings with an angle more than 70 degrees may provide slightly better performance, the former is selected to provide a margin of error that can occur when controllers are implemented in the field. The selected range of operation is circled in Figure 4.3(a).

Tables 4-1, 4-2, and 4-3 present the variation of $Q_{\text {deviation, }} \mathrm{Q}_{\mathrm{avg}}$, and $\Delta \mathrm{V}$ with the slope of the Volt-VAR controller characteristic. From the tables, it can be seen that increasing the voltage setpoint beyond $1.1 \mathrm{pu}$ increases the voltage deviations at the feeder ends. Also, the performance of the volt-var controller does not change much when the voltage set-point is increased beyond $1.1 \mathrm{pu}$. 


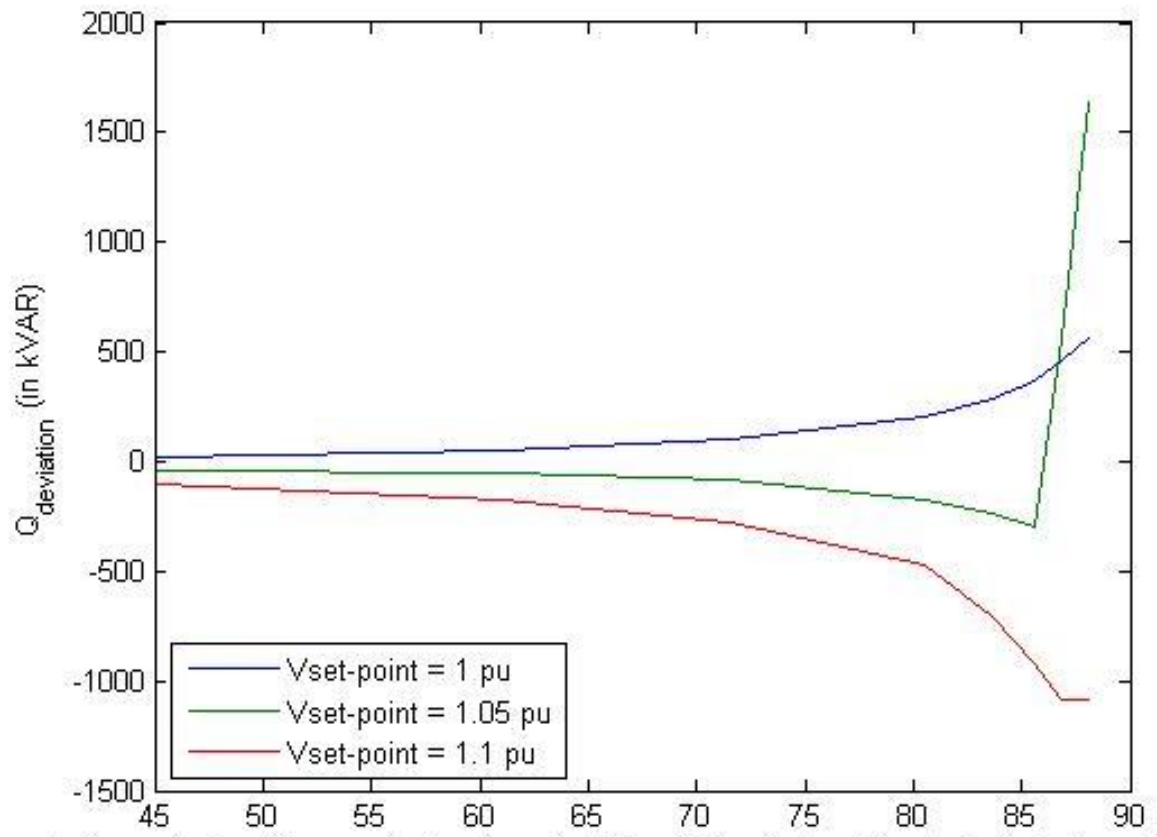

Angle made by volt-var controller characteristic with the horizontal axis in clockwise direction

(a)

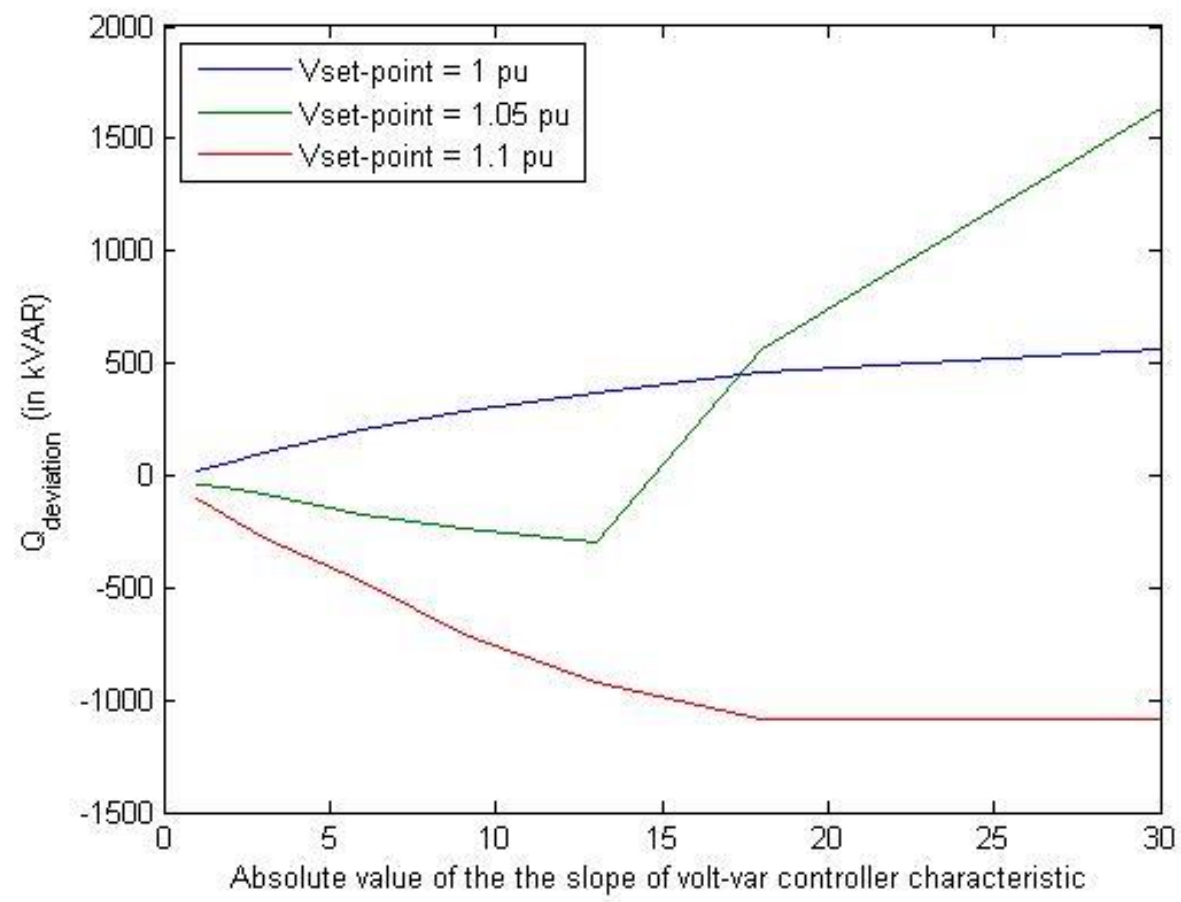

(b)

Figure 4.1 $Q_{\text {deviation }}$ Vs slope of Volt-VAR controller characteristic 


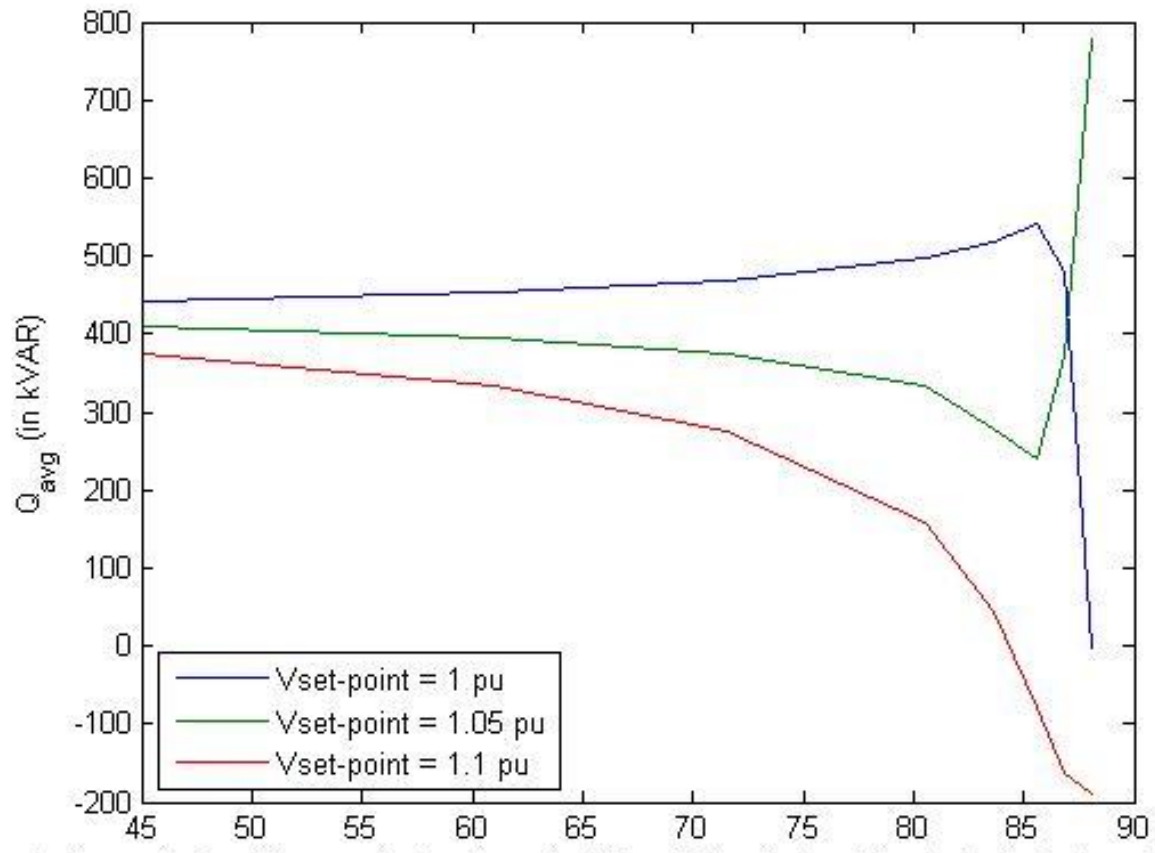

Angle made by volt-var controller characteristic with the horizontal axis in clockwise direction

(a)

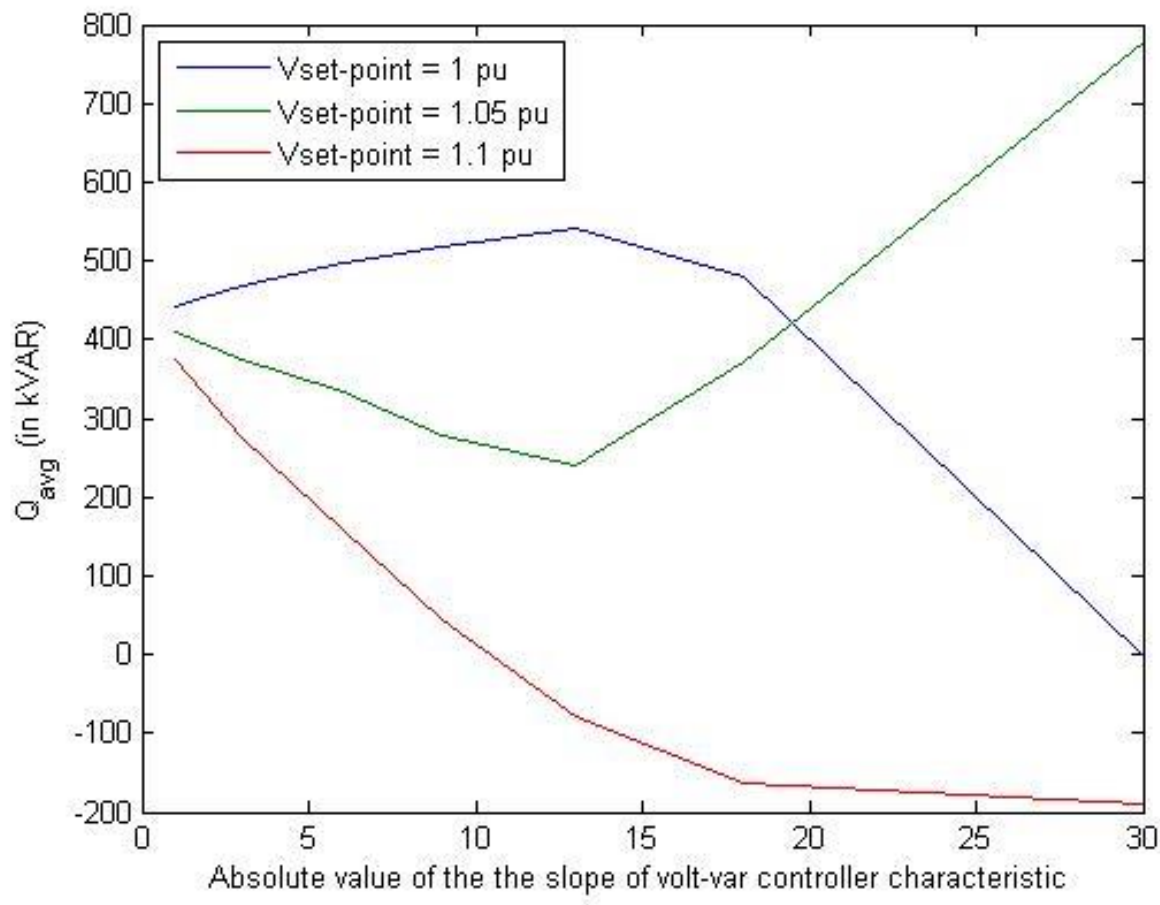

(b)

Figure 4.2 $Q_{\text {avg }}$ vs slope of Volt-VAR controller characteristic 


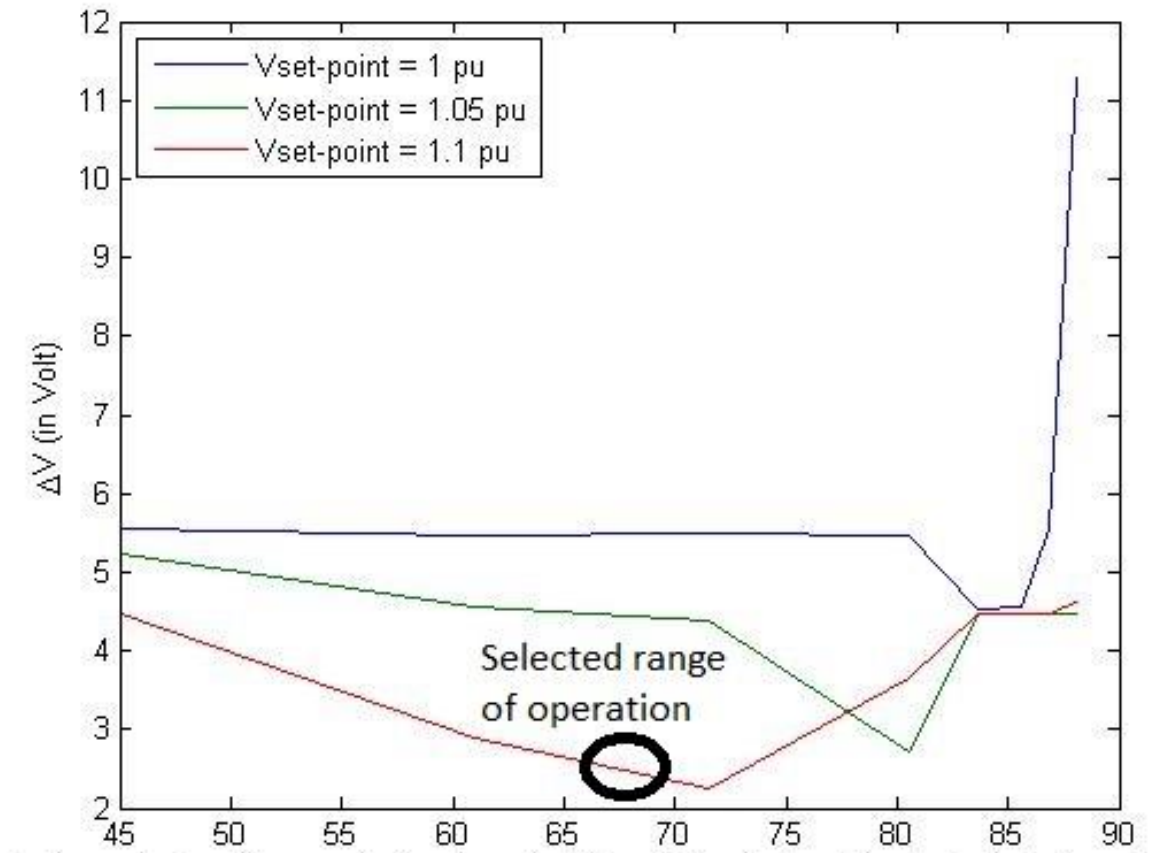

Angle made by volt-var controller characteristic with the horizontal axis in clockwise direction

(a)

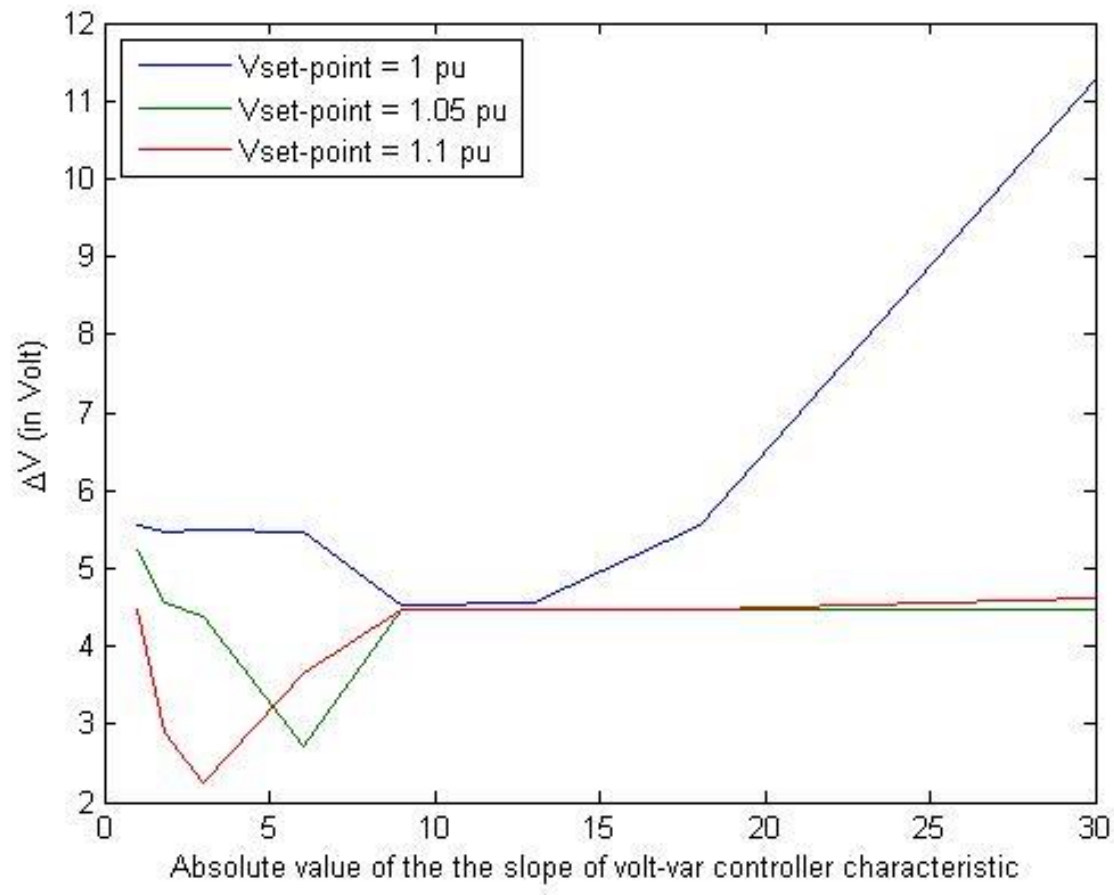

(b)

Figure 4.3 $\Delta V$ vs slope of Volt-VAR controller characteristic 
Table 4-1 $Q_{\text {deviation }}$ vs slope of volt-var controller characteristic with varying voltage set-points

\begin{tabular}{|c|c|c|c|c|c|c|}
\hline \multirow[b]{2}{*}{$\begin{array}{l}\text { Absolute } \\
\text { value of } \\
\text { slope of } \\
\text { volt-var } \\
\text { curve }\end{array}$} & \multirow[b]{2}{*}{$\begin{array}{l}\text { Angle* made } \\
\text { by the vot- } \\
\text { var curve } \\
\text { with } x \text {-axis in } \\
\text { degrees }\end{array}$} & \multicolumn{5}{|c|}{ Qdeviation in kVAR with varying voltage set-point } \\
\hline & & $\begin{array}{l}\text { Voltage } \\
\text { set-point } \\
=1 \mathrm{pu}\end{array}$ & $\begin{array}{l}\text { Voltage } \\
\text { set-point } \\
=1.05 \mathrm{pu}\end{array}$ & $\begin{array}{l}\text { Voltage } \\
\text { set-point } \\
=1.1 \mathrm{pu}\end{array}$ & $\begin{array}{l}\text { Voltage } \\
\text { set-point } \\
=1.2 \mathrm{pu}\end{array}$ & $\begin{array}{l}\text { Voltage } \\
\text { set-point } \\
=1.3 \mathrm{pu}\end{array}$ \\
\hline 1 & 45 & 20 & -39 & -107 & -229 & -344 \\
\hline 1.8 & 61 & 52 & -56 & -179 & -379 & -583 \\
\hline 3 & 71.57 & 101 & -79 & -273 & & \\
\hline 6 & 80.54 & 203 & -175 & -476 & -1089 & -1089 \\
\hline 9 & 83.67 & 287 & -235 & -708 & -1089 & -1089 \\
\hline 13 & 85.61 & 370 & -298 & -917 & -1089 & -1089 \\
\hline 18 & 86.83 & 461 & 567 & -1089 & -1089 & -1089 \\
\hline 30 & 88.1 & 562 & 1634 & -1089 & -1089 & -1089 \\
\hline
\end{tabular}

*The angle made by the volt-var characteristic curve is measured from the horizontal axis (xaxis) in the clockwise direction.

Table 4-2 Qavg vs slope of volt-var controller characteristic with varying voltage set-points

\begin{tabular}{|c|c|c|c|c|c|c|}
\hline \multirow[b]{2}{*}{$\begin{array}{c}\text { Absolute } \\
\text { value of } \\
\text { slope of } \\
\text { volt-var } \\
\text { curve }\end{array}$} & \multirow[b]{2}{*}{$\begin{array}{l}\text { Angle* made } \\
\text { by the vot- } \\
\text { var curve } \\
\text { with } x \text {-axis in } \\
\text { degrees }\end{array}$} & \multicolumn{5}{|c|}{ Qavg in kVAR with varying voltage set-point in per unit } \\
\hline & & $\begin{array}{l}\text { Voltage } \\
\text { set-point } \\
=1 \mathrm{pu}\end{array}$ & $\begin{array}{c}\text { Voltage } \\
\text { set-point } \\
=1.05 \mathrm{pu}\end{array}$ & $\begin{array}{l}\text { Voltage } \\
\text { set-point } \\
=1.1 \mathrm{pu}\end{array}$ & $\begin{array}{l}\text { Voltage } \\
\text { set-point } \\
=1.2 \mathrm{pu}\end{array}$ & $\begin{array}{l}\text { Voltage } \\
\text { set-point } \\
=1.3 \mathrm{pu}\end{array}$ \\
\hline 1 & 45 & 442 & 409 & 375 & 306 & 236 \\
\hline 1.8 & 61 & 453 & 395 & 335 & 213 & 97 \\
\hline 3 & 71.57 & 467 & 375 & 276 & & \\
\hline 6 & 80.54 & 496 & 333 & 158 & -183 & -190 \\
\hline 9 & 83.67 & 519 & 278 & 43 & -190 & -190 \\
\hline 13 & 85.61 & 542 & 241 & -80 & -190 & -190 \\
\hline 18 & 86.83 & 479 & 372 & -162 & -190 & -190 \\
\hline 30 & 88.1 & -2 & 779 & -190 & -190 & -190 \\
\hline
\end{tabular}

*The angle made by the volt-var characteristic curve is measured from the horizontal axis (xaxis) in the clockwise direction. 
Table 4-3 $\Delta V$ vs slope of volt-var controller characteristic with varying voltage set-point

\begin{tabular}{|c|c|c|c|c|c|c|}
\hline \multirow[b]{2}{*}{$\begin{array}{l}\text { Absolute } \\
\text { value of } \\
\text { slope of } \\
\text { volt-var } \\
\text { curve }\end{array}$} & \multirow[b]{2}{*}{$\begin{array}{l}\text { Angle* made } \\
\text { by the vot- } \\
\text { var curve } \\
\text { with } x \text {-axis in } \\
\text { degrees }\end{array}$} & \multicolumn{5}{|c|}{$\Delta \mathrm{V}$ in volt with varying voltage set-point in per unit } \\
\hline & & $\begin{array}{l}\text { Voltage } \\
\text { set-point } \\
=1 \mathrm{pu}\end{array}$ & $\begin{array}{l}\text { Voltage } \\
\text { set-point } \\
=1.05 \mathrm{pu}\end{array}$ & $\begin{array}{l}\text { Voltage } \\
\text { set-point } \\
=1.1 \mathrm{pu}\end{array}$ & $\begin{array}{l}\text { Voltage } \\
\text { set-point } \\
=1.2 \mathrm{pu}\end{array}$ & $\begin{array}{l}\text { Voltage } \\
\text { set-point } \\
=1.3 \mathrm{pu}\end{array}$ \\
\hline 1 & 45 & 5.55 & 5.23 & 4.47 & 2.53 & 4.21 \\
\hline 1.8 & 61 & 5.47 & 4.57 & 2.88 & 4.2 & 3.74 \\
\hline 3 & 71.57 & 5.49 & 4.39 & 2.24 & & \\
\hline 6 & 80.54 & 5.47 & 2.73 & 3.65 & 4.54 & 4.63 \\
\hline 9 & 83.67 & 4.54 & 4.47 & 4.47 & 4.63 & 4.63 \\
\hline 13 & 85.61 & 4.55 & 4.47 & 4.47 & 4.63 & 4.63 \\
\hline 18 & 86.83 & 5.55 & 4.47 & 4.47 & 4.63 & 4.63 \\
\hline 30 & 88.1 & 11.28 & 4.47 & 4.63 & 4.63 & 4.63 \\
\hline
\end{tabular}

*The angle made by the volt-var characteristic curve is measured from the horizontal axis (xaxis) in the clockwise direction. 


\section{Performance of Constant Power Factor Controller}

In order to study the performance of the constant power factor controller, simulations were performed at different power factors values for both leading and lagging modes.

Figure 5.1 shows the variation of Qdeviation with varying power factor for both leading and lagging modes. Figures 5.2 and 5.3 present the variation in average reactive power drawn from the substation $\left(\mathrm{Q}_{\mathrm{avg}}\right)$ and voltage deviation $(\Delta \mathrm{V})$, respectively, with variation in power factor of the PV generator.

The following observations can be made from figures 5.1, 5.2, and 5.3 for the power factor lagging mode:

- $Q_{\text {deviation }}$ increases with increasing power factor, but the $Q_{\text {deviation }}$ values are always less than zero (Figure 5.1). This implies that the maximum reactive power drawn from the substation when the PV generator is run in power factor lagging mode is always less than the reactive power drawn from the substation in the absence of the PV generator $\left(Q_{\text {ref }}\right)$.

- The average reactive power drawn from the substation $\left(Q_{a v g}\right)$ increases with increasing power factor values (Figure 5.2).

- Voltage deviation $(\Delta \mathrm{V})$ values do not change significantly with power factor and lie between 5 and $6 \mathrm{~V}$ for the power factor values between 0.9 and 1 (Figure 5.3).

The following can be seen from figures 5.1, 5.2, and 5.3 for the power factor leading mode:

- $Q_{\text {deviation }}$ decreases with increasing power factor magnitude, where the $Q_{\text {deviation }}$ values are always greater than zero (Figure 5.1). This implies that the maximum reactive power drawn from the substation when the PV generator is run in power factor leading mode is always greater than the reactive power drawn from the substation in the absence of the PV generator $\left(Q_{\text {ref }}\right)$.

- The average reactive power drawn from the substation $\left(Q_{a v g}\right)$ decreases when the magnitude of power factor increases from 0.9 to 0.98 (Figure 5.2).

- For power factors between 0.92 and 0.98 , voltage deviation $(\Delta \mathrm{V})$ values are low and lie between 1.56 and $2.38 \mathrm{~V}$ (Figure 5.3). 


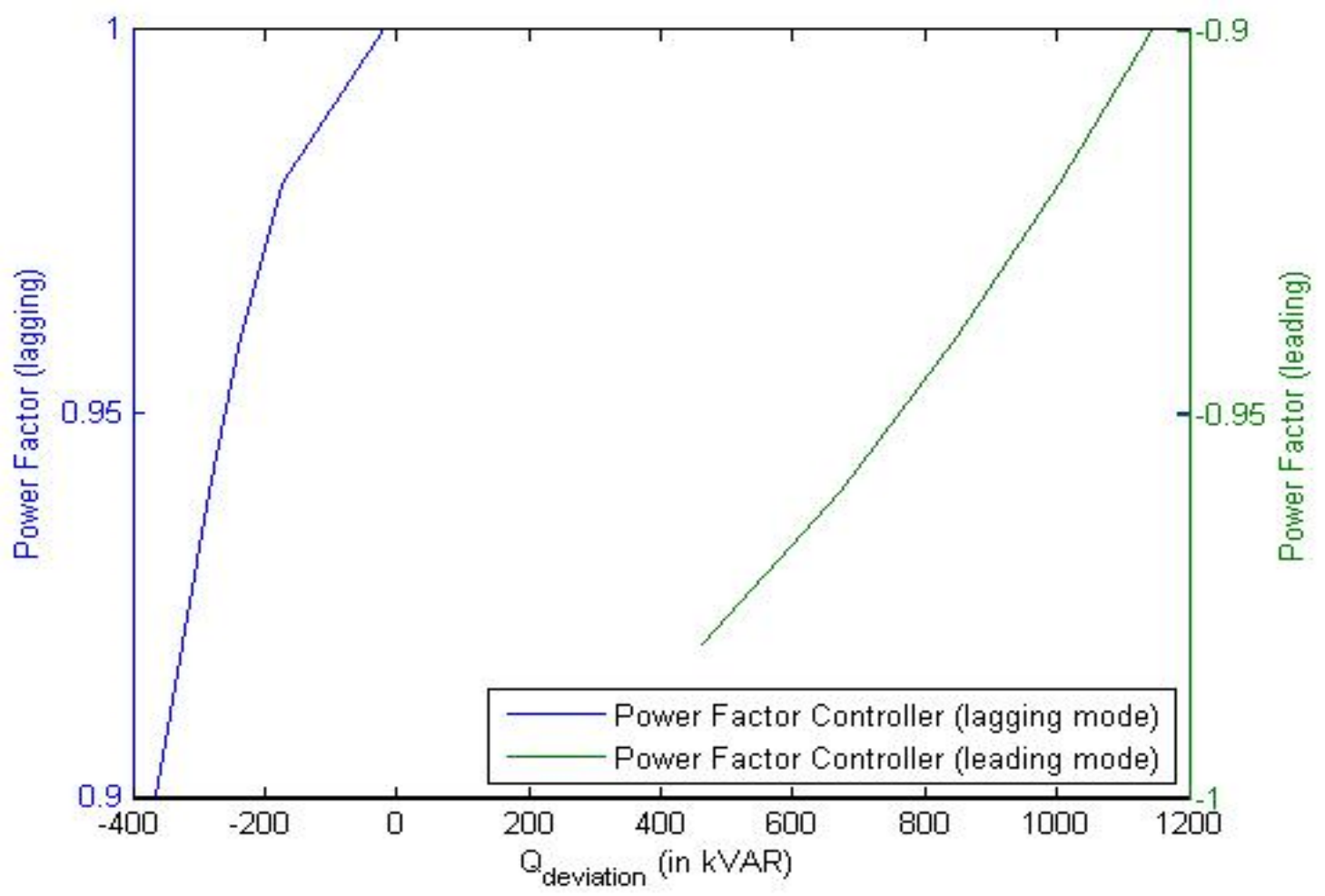

Figure 5.1 Qdeviation vs Power factor

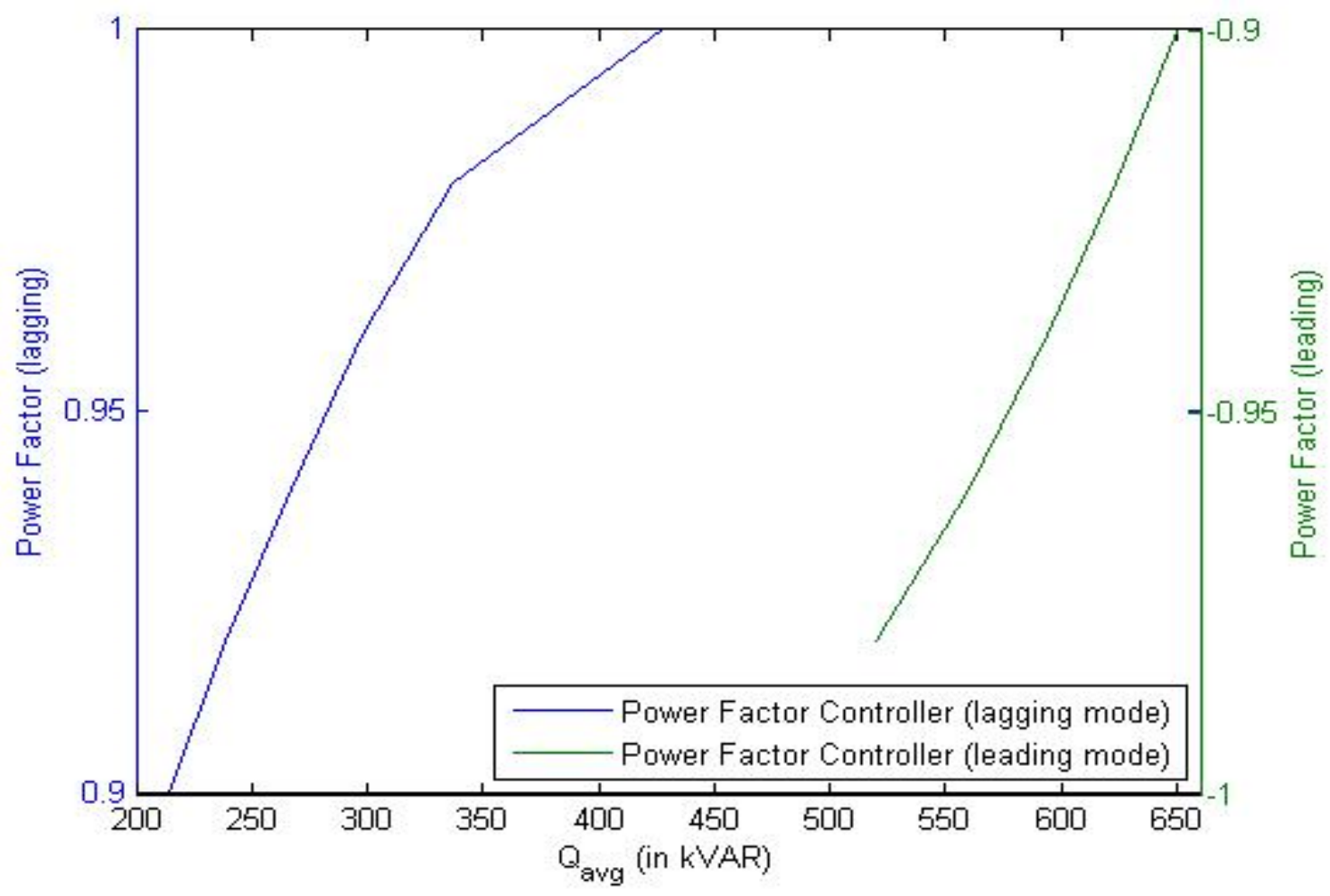

Figure 5.2 Qavg vs Power factor 


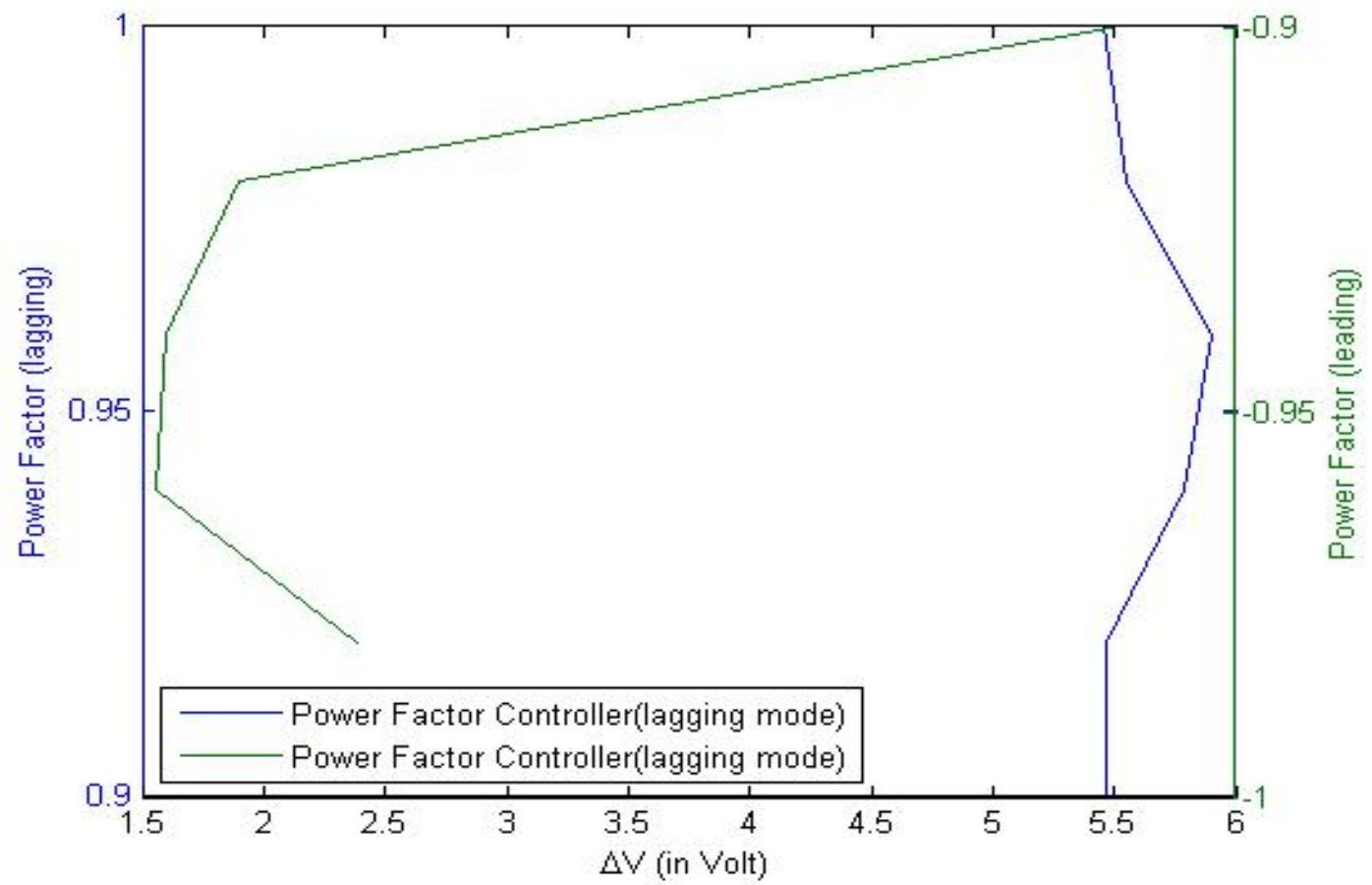

Figure 5.3 $\Delta \mathrm{V}$ vs Power factor

Tables 5-1 and 5-2 present the performances of constant power factor controller in lagging and leading modes respectively.

Table 5-1 Performance of constant power factor controller in power factor lagging mode

\begin{tabular}{|c|c|c|c|c|}
\hline Power Factor & $\mathbf{Q}_{\max }$ (kVAR) & $\mathbf{Q}_{\text {deviation }}$ (kVAR) & $\mathbf{Q}_{\text {avg }}$ (kVAR) & $\Delta \mathbf{V}$ (volt) \\
\hline .9 & 954 & -366 & 214 & 5.47 \\
\hline .92 & 994 & -326 & 239 & 5.47 \\
\hline .94 & 1035 & -285 & 267 & 5.79 \\
\hline .96 & 1084 & -236 & 298 & 5.90 \\
\hline .98 & 1146 & -174 & 337 & 5.55 \\
\hline 1 & 1302 & -18 & 428 & 5.46 \\
\hline
\end{tabular}

Table 5-2 Performance of constant power factor controller in power factor leading mode

\begin{tabular}{|c|c|c|c|c|}
\hline Power Factor & $\mathbf{Q}_{\max }(\mathbf{k V A R})$ & $\mathbf{Q}_{\text {deviation }}$ (kVAR) & $\mathbf{Q}_{\text {avg }}$ (kVAR) & $\Delta \mathbf{V}$ (volt) \\
\hline-.9 & 2464 & 1144 & 650 & 5.51 \\
\hline-.92 & 2324 & 1004 & 623 & 1.90 \\
\hline-.94 & 2168 & 848 & 594 & 1.60 \\
\hline-.96 & 1993 & 673 & 560 & 1.56 \\
\hline-.98 & 1781 & 461 & 520 & 2.38 \\
\hline
\end{tabular}


From figures 5.1, 5.2, and 5.3, it can be seen that operating the PV generator at a lagging power factor minimizes the reactive power drawn from the substation, but it increases the voltage deviations. On the other hand, operating the PV generator in leading power factor mode minimizes the voltage deviation at the feeder ends at the cost of drawing more reactive from the substation. This finding was used to develop the idea for a new type of controller, called 'switch controller'. The basic idea behind switch controller and the evaluation of its performance is described in the following subsection.

\subsection{Switch Controllers}

As discussed earlier, operating the PV generator at a lagging power factor minimizes the reactive power drawn from the substation at the expense of increasing the voltage deviations at the customer end. On the other hand, operating the PV generator in leading power factor mode minimizes the voltage deviations at the feeder end at the cost of drawing more reactive from the substation. The idea of switch controllers was developed by switching the power factor from leading to lagging when the solar generation started to increase continuously and from lagging to leading when the generation started to decrease continuously. For this, three time periods were identified when the solar generation was either continuously increasing or decreasing. These time periods are shown in Table 5-3.

As can be seen from the Table 5-3, the solar generation continuously increased during T2 and it continuously decreased during T1 and T3. The performances of constant power factor controller at a power factor of 0.94 both in leading and lagging modes were evaluated for the times periods T1, T2, T3. Table 5-4 shows the performances of constant power factor controllers during this these time periods. It can be seen that the performances of power factor controllers are similar during the three time periods irrespective of whether the generation is increasing or decreasing. Also, the performances of the controller in leading or lagging mode during the three

time periods $(T 1, T 2, T 3)$ were not different from the performance of the controller during the entire duration of analysis. 
Table 5-3 Time periods when solar generation continuously increases or decreases

\begin{tabular}{|c|c|}
\hline Time Period & Solar Geneation \\
\hline T1: $14: 22: 04-14: 22: 29$ & Decreasing \\
\hline T2: $14: 22: 35-14: 22: 48$ & Increasing \\
\hline T3: $14: 22: 54-14: 23: 07$ & Decreasing \\
\hline
\end{tabular}

Table 5-4 Performance of constant power factor controller when the solar generation continuously increases or decreases

\begin{tabular}{|c|c|c|c|}
\hline Power Factor & Duration of Analysis & Qdeviation (kVAR) & $\Delta \mathbf{V}$ (volt) \\
\hline 0.94 & T1 & -340 & 5.21 \\
\hline 0.94 & T2 & -341 & 4.75 \\
\hline 0.94 & T3 & -426 & 4.79 \\
\hline 0.94 & Full & -285 & 5.79 \\
\hline-0.94 & T1 & 775 & 1.26 \\
\hline-0.94 & T2 & 770 & 1.30 \\
\hline-0.94 & T3 & 815 & 1.19 \\
\hline-0.94 & Full & 848 & 1.60 \\
\hline
\end{tabular}

This suggests that if we switch the controller from leading to lagging during the period when solar generation increases continuously, we will be able to limit the reactive power flowing from the substation during the period when the controllers are switched but won't be able to regulate the voltage at the customer end. On the other hand, switching the controller from lagging to leading when the solar generation decreases continuously will control voltage deviations at the customer ends but will draw large amounts of reactive power from the substation. 


\section{Comparison of Controller Performances}

This section compares the performances of the two feedback control strategies. To compare the performance of the Volt-VAR control with the constant power factor control, two different constant power factor controllers will be used. In comparing the reactive power drawn from the substation, the lagging power factor control is used, and in comparing the voltage deviation the leading power factor control is used.

As discussed in Section 4, a Volt-VAR controller with a voltage set-point of $1.1 \mathrm{pu}$, which makes an angle of 65-70 degrees with the horizontal axis in clockwise direction, is selected for comparison with the constant power factor control.

Figures 6.1 and 6.2 compare the performance of Volt-VAR and constant power factor control in lagging mode as to $Q_{\text {deviation }}$ and $Q_{\text {avg. }}$. The following observations can be made from these figures:

- For the selected range of operation of the Volt-VAR controller, $Q_{\text {deviation }}$ is higher for the Volt-VAR controller when the power factor is less than 0.96 . Qdeviation is lower for the VoltVAR controller when the power factor is more than 0.96 (Figure 6.1).

- $Q_{\text {avg }}$ follows the same trend as $Q_{\text {deviation }}$ (Figure 6.2).

It should be noted that the voltage deviation values at the feeder ends $(\Delta V)$ are always higher for the power factor controller in lagging mode as compared to that for the Volt-VAR controller with a voltage set-point of $1.1 \mathrm{pu}$ (Figure 6.3).

Figures 6.4, 6.5, and 6.6 compare the performances of the Volt-VAR controller and the power factor controller in leading mode. It should also be noted that the $Q_{\text {deviation }}$ and $Q_{\text {avg }}$ for the VoltVAR controller are always lower than those obtained using a constant power factor controller in leading mode (Figures $6.4 \& 6.5$ ).

Figure 6.6 compares the performances of the Volt-VAR controller and constant power factor controller in leading mode on the basis of $\Delta \mathrm{V}$. It can be seen from Figure 6.3 that for the selected range of operation of the Volt-VAR controller, $\triangle \mathrm{V}$ is higher than that obtained from a power factor controller operating at a leading power factor of 0.92 or higher. 


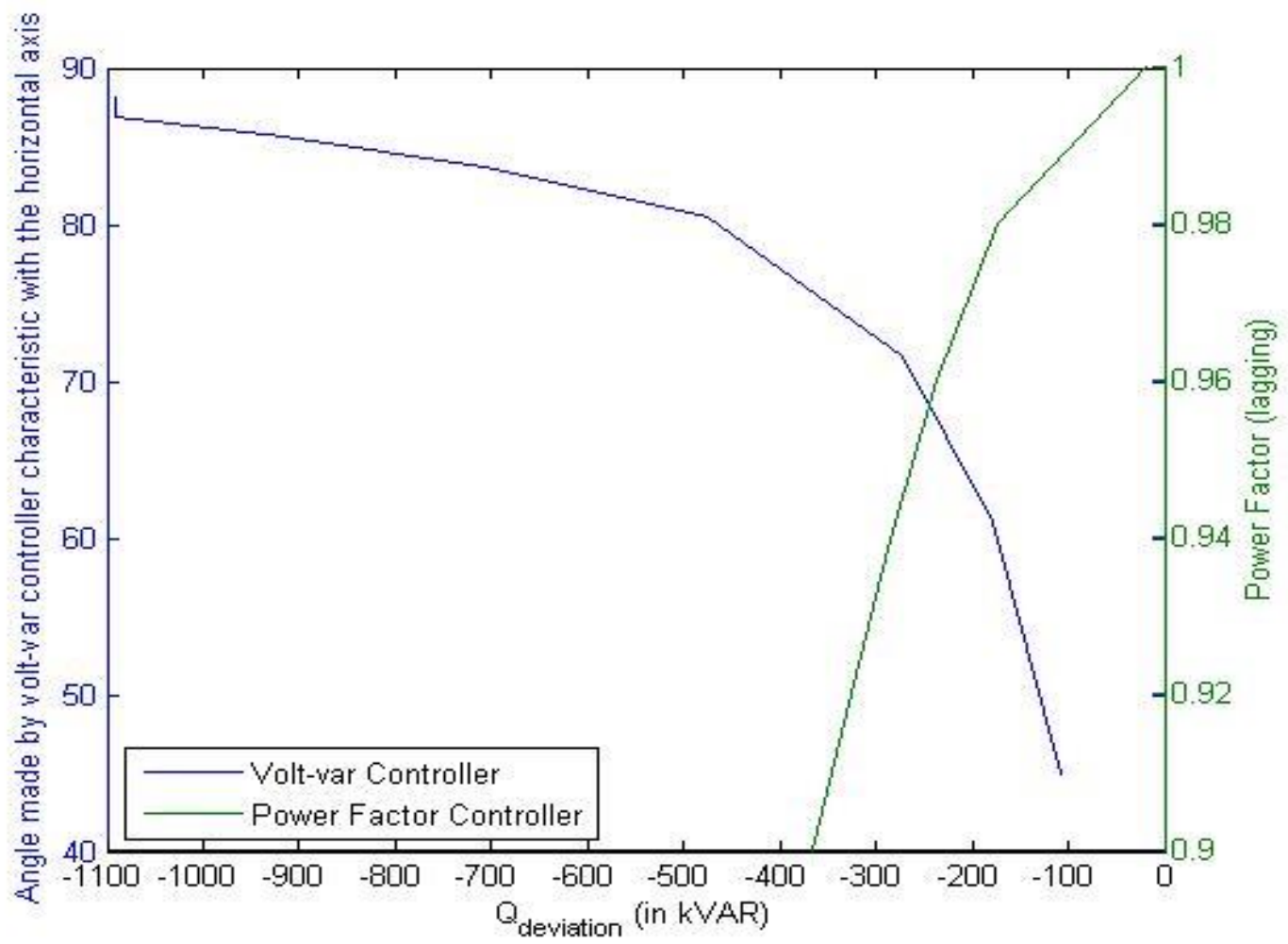

Figure 6.1 $Q_{\text {deviation }}$ for Volt-VAR controller $\left(\mathrm{V}_{\text {set-point }}=1.1 \mathrm{pu}\right)$ \& power factor controller (lagging mode)

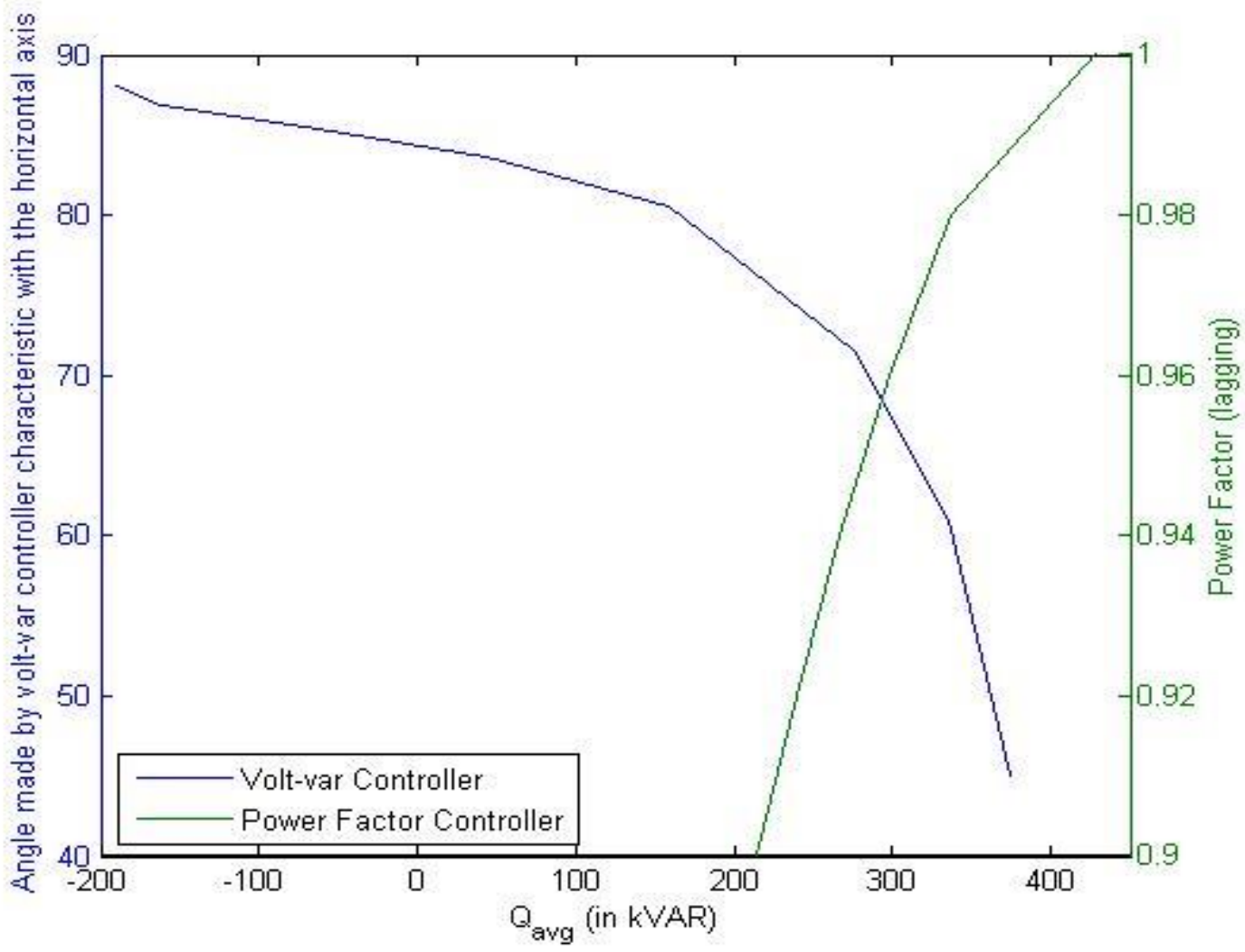

Figure 6.2 $Q_{\text {avg }}$ for Volt-VAR controller $\left(V_{\text {set-point }}=1.1 \mathrm{pu}\right)$ \& power factor controller (lagging mode) 


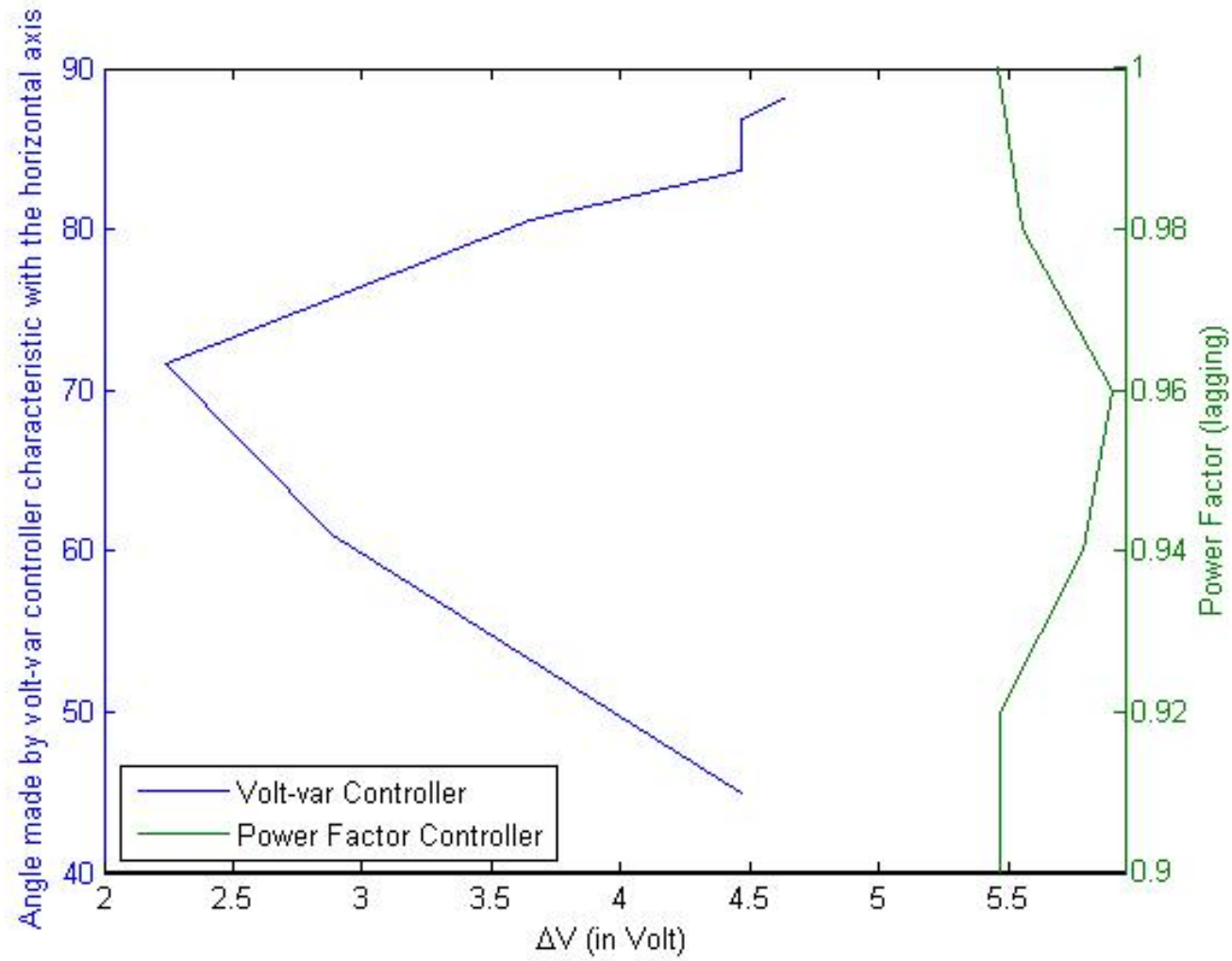

Figure 6.3 $\Delta \mathrm{V}$ for Volt-VAR controller $\left(\mathrm{V}_{\text {set-point }}=1.1 \mathrm{pu}\right)$ \& power factor controller (lagging mode)

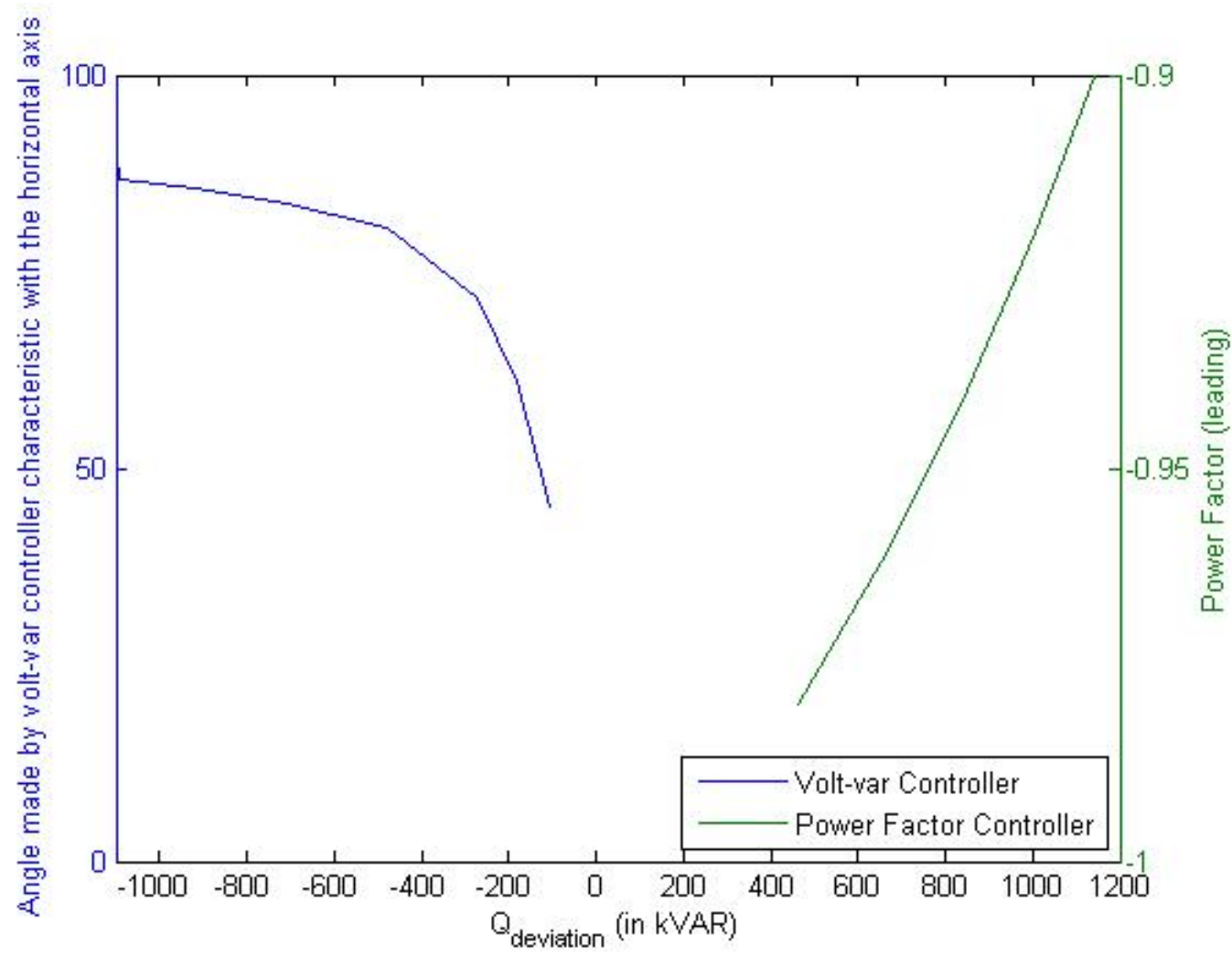

Figure 6.4 $Q_{\text {deviation }}$ for Volt-VAR controller $\left(V_{\text {set-point }}=1.1 \mathrm{pu}\right)$ \& power factor controller (leading mode) 


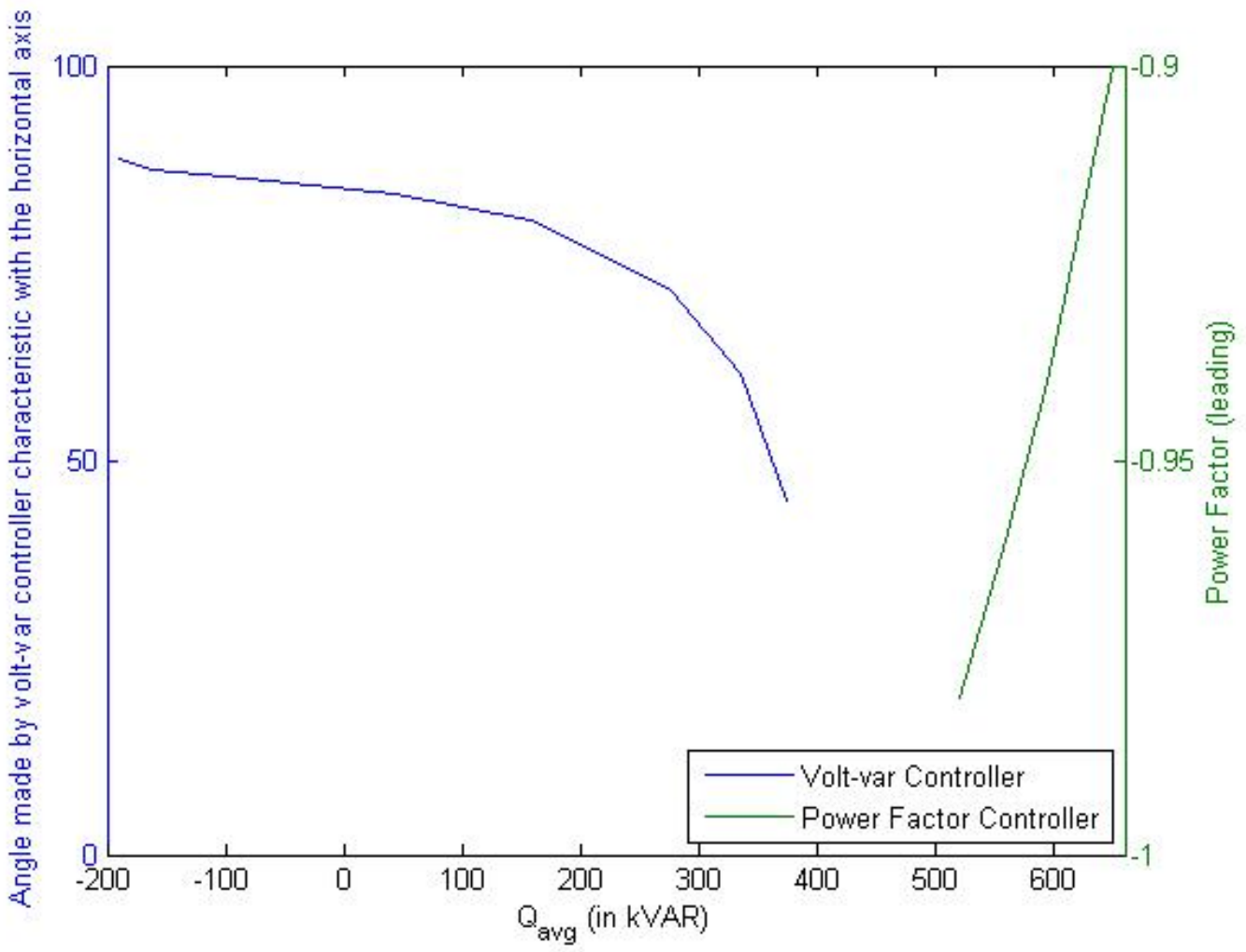

Figure 6.5 $Q_{\text {avg }}$ for Volt-VAR controller ( $V_{\text {set-point }}=1.1 \mathrm{pu}$ ) \& power factor controller (leading mode)

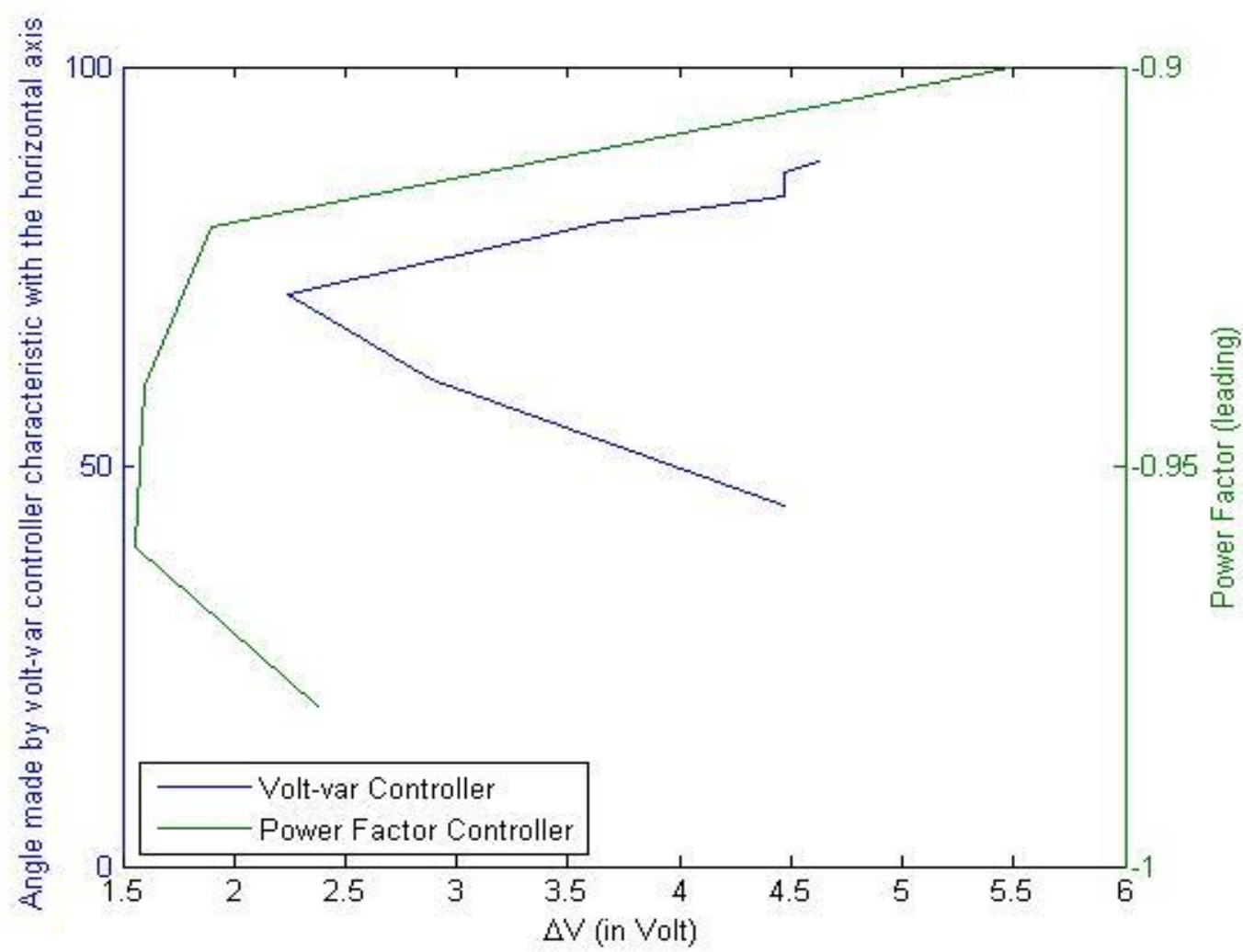

Figure 6.6 $\Delta \mathrm{V}$ for Volt-VAR controller $\left(\mathrm{V}_{\text {set-point }}=1.1 \mathrm{pu}\right)$ \& power factor controller (leading mode) 


\section{Conclusion}

Parametric studies were run for both Volt-VAR and power factor controllers, and the performance of the controllers were compared as to transmission system reactive power demands and customer level voltage deviations. In the control comparisons it was found that the constant power factor controller operating in lagging mode minimizes the reactive power drawn from the substation at the expense of increased customer level voltage deviations. On the other hand, the power factor controller operating in leading mode minimizes the customer level voltage deviations at the expense of increasing the reactive power drawn from the substation.

Simulation results show that the voltage deviation is lower for the Volt-VAR controller in the selected range of operation as compared to that obtained for the constant power factor controller operating in the lagging mode. On the other hand, maximum reactive power and average reactive power drawn from the substation are lower for the Volt-VAR controller in the selected range of operation as compared to those obtained for constant power factor controller operating in leading mode. However, in the study here the constant power factor controller operating in the leading mode provides better voltage control than the Volt-VAR controller.

The choice of controller to be implemented should be based on both transmission and distribution system concerns. If the major aim is to regulate the transmission system voltage, a controller which draws the least amount of reactive power from the substation should be used. Constant power factor controllers operating in lagging mode are suitable for this. On the other hand, if the major aim is to reduce voltage fluctuations in the distribution system, a controller which best regulates the voltage at the customer end should be used. In the study here, constant power factor controllers operating in leading mode are best suited for this. If the aim is to take into account both concerns, then the Volt-VAR controller could be a good compromise.

The current study investigated and compared the performances of Volt-VAR and constant power factor controllers in case of one PV generator present in the system. Future work could evaluate the performance of controllers when multiple PV generators are present in the system. Analysis can be performed to study how the performance changes for a given controller when different PV generators in the system are controlled by different types of controllers. 
Performance of a new type of controller which regulates the power factor of the PV generator based on its terminal voltage can also be evaluated. 


\section{References}

[1] United States Department of Energy, SunShot Vison Study, Report DOE/GO-102012-3037, Feb. 2012. Available at: < http://www1.eere.energy.gov/solar/sunshot/vision_study.html>.

[2] G K Singh, "Solar power generation by PV (photovoltaic) technology: A review", Energy, vol. 53, pp. 1-13, 2013.

[3] North American Electric Reliability Corporation, "Accommodating high levels of variable generation." April 2009.

[4] F. Katiraei, and J. R. Agüero, "Solar PV integration challenges," Power and Energy Magazine, IEEE , vol.9, no.3, pp.62,71, May-June 2011.

[5] W. Zhang, M. Baran, A. De, and S. Bhattacharya, "Fast volt-VAR control on PV dominated distribution systems," 2014 IEEE PES T\&D Conference and Exposition, vol., no., pp.1,5, 14-17 April 2014.

[6] W. Shang, and M.A. Redfern, "A new control scheme for a distributed generator providing network voltage support," 2011 International Conference on Advanced Power System Automation and Protection (APAP), vol.3, no., pp.2453,2457, 16-20 Oct. 2011.

[7] O. Phochai, W. Ongsakul, and J. Mitra, "Voltage control strategies for grid-connected solar PV systems," 2014 International Conference and Utility Exhibition on Green Energy for Sustainable Development (ICUE), vol., no., pp.1,7, 19-21 March 2014.

[8] K. Kouno, M. Hirose, T. Nagase, and W. Hashimoto, W.; Hojo, M.; Ohnishi, T., "Effectiveness of constant power factor control of mega-solar system for voltage regulation with long distribution line," 2013 IEEE 10th International Conference on Power Electronics and Drive Systems (PEDS), vol., no., pp.317,322, 22-25 April 2013.

[9] E. Demirok, P. Casado González, K.H.B. Frederiksen, D. Sera, P. Rodriguez, and R. Teodorescu, "Local reactive power control methods for overvoltage prevention of distributed solar inverters in low-voltage grids," IEEE Journal of Photovoltaics, vol.1, no.2, pp.174,182, Oct. 2011.

[10] J.W. Smith, W. Sunderman, R. Dugan, and B. Seal, "Smart inverter volt/var control functions for high penetration of PV on distribution systems," 2011 IEEE/PES Power Systems Conference and Exposition (PSCE), vol., no., pp.1,6, 20-23 March 2011.

[11] H. Alatrash, R.A. Amarin, and C. Lam, "Enabling large-Scale PV integration into the Grid," 2012 IEEE Green Technologies Conference, vol., no., pp.1,6, 19-20 April 2012.

[12] W. Shang, S. Zheng, L. Li, and M. Redfern, "A new volt/VAR control for distributed generation," 2013 48th International Universities' Power Engineering Conference (UPEC), vol., no., pp.1,5, 2-5 Sept. 2013.

[13] J. Jung, A. Onen, K. Russell, R.P. Broadwater, S. Steffel, and A. Dinkel, "Configurable, hierarchical, model-based, scheduling control with photovoltaic generators in power distribution circuits", Renewable Energy, vol. 76, pp. 318-329, 2015. 